\title{
The Characterization of a Piston Displacement-Type Flowmeter Calibration Facility and the Calibration and Use of Pulsed Output Type Flowmeters
}

\section{G. E. Mattingly}

National Institute of Standards and Technology, Gaithersburg, MD 20899

\author{
Critical measurement performance of \\ fluid flowmeters requires proper and \\ quantified verification data. These data \\ should be generated using calibration \\ and traceability techniques established \\ for these verification purposes. In these \\ calibration techniques, the calibration \\ facility should be well-characterized and \\ its components and performance prop- \\ erly traced to pertinent higher stan- \\ dards. The use of this calibrator to \\ calibrate flowmeters should be appropri- \\ ately established and the manner in \\ which the calibrated flowmeter is used \\ should be specified in accord with the \\ conditions of the calibration. \\ These three steps: 1) characterizing \\ the calibration facility itself, 2) using the \\ characterized facility to calibrate a \\ flowmeter, and 3) using the calibrated
}

\begin{abstract}
flowmeter to make a measurement are described and the pertinent equations are given for an encoded-stroke, piston displacement-type calibrator and a pulsed output flowmeter. It is concluded that, given these equations and proper instrumentation of this type of calibrator, very high levels of performance can be attained and, in turn, these can be used to achieve high fluid flow rate measurement accuracy with pulsed output flowmeters.
\end{abstract}

Key words: flow measurement; fluid meter characterization; meter performance; output flowmeter; turbine flowmeter; volumetric calibrator.

Accepted: June 29, 1992

\section{Contents}

Glossary $\ldots \ldots \ldots \ldots \ldots \ldots \ldots \ldots \ldots \ldots \ldots, 510$

1. Introduction $\ldots \ldots \ldots \ldots \ldots \ldots \ldots \ldots \ldots, 512$

2. Calibrator Characterization........... 513

2.1 Geometrical Determination at

Reference Conditions............ 513

2.2 Geometrical Determination at Non-Reference Conditions ......... 514

2.3 Determination of Calibrator Constant by the Draw Technique in Reference Conditions ...................... 515

2.4 Determination of Calibrator Constant by the Draw Technique in Non-Reference Conditions......... 516

3. Calibrator Use in Calibrating a Turbine-Type Flowmeter. 518
3.1 Reference Conditions............. 518

3.2 Non-Reference Conditions ......... 521

4. Using a Turbine-Type Flowmeter

to Make a Measurement ............ 522

4.1 Reference Conditions............. 522

4.2 Non-Reference Conditions .......... 523

5. Discussion........................ 523

6. Conclusions ...................... 525

7. Appendix A. Cross-Sectional Area

Changes in the Cylinder of the Calibrator ........... 526

8. Appendix B. Turbine Meter Data

Processing............. 527

9. Appendix C. Equations Summary...... 529

10. References .................... 531 


\section{Glossary}

Symbol

$A_{\infty}, A_{\mathrm{C}}$

$A_{\text {ro }}, A$

$$
C_{0}, C
$$$$
d_{0}, d
$$

$$
D_{0}, D
$$

Outside diameter of turbine propeller at reference and non-reference conditions, respectively.

$D_{\mathrm{Co}}, D_{\mathrm{C}} \quad$ Inside diameter of the cylinder of the calibrator at reference and nonreference conditions, respectively.

$D_{\mathrm{To}}, D_{\mathrm{T}} \quad$ Outside diameter of the tube connected to the calibrator piston at reference and nonreference conditions, respectively.

$E_{\mathrm{C}} \quad$ Modulus of elasticity of the material of the calibrator cylinder at pertinent conditions.. tubes connected to calibrator piston at reference conditions, respectively.

cal body in unstressed and stressed conditions, respectively. to calibrator piston at reference and non-reference conditions, respectively.

Inner diameter of calibrator
Dimensions $\quad E_{F}$

$\mathbf{L}^{2}$

$\mathbf{L}^{2}$

$E_{\mathrm{T}}$

where

used, denote averages over

L

L

L

\section{$K_{\mathbf{C}}^{\prime}$}

L

$$
K_{\mathrm{C} 0}, K_{\mathrm{C}}
$$

L

L

$\mathrm{F} / \mathrm{L}^{2}$
Symbol

$E_{\mathrm{M}}$

$K_{\mathrm{E} 0}, K_{\mathrm{E}}$

$f_{M 0}, f_{M}$

$$
K_{\mathrm{M} 0}, K_{\mathrm{M}}
$$

\section{Description}

Modulus of elasticity of the fluid at pertinent conditions.

Modulus of elasticity of the material of the body of the flowmeter at pertinent conditions.

Modulus of elasticity of the material of the tube connected to the calibrator piston at pertinent conditions.

Frequency of pulses from encoder at reference and non-reference conditions, respectively.

Frequencies of pulses from the flowmeter at reference and nonreference conditions respectively.

Encoder constant at reference and nonreference conditions, respectively.

Calibrator constant at reference and nonreference conditions, respectively.

Calibrator constant in pulses per fluid volume collected in collection vessel.

Meter factor at reference and non-reference conditions, respectively. Where over-bars are used is meant the average value over a Reynolds number range.

$L_{\mathrm{E} 0}, L_{\mathrm{E}} \quad$ Piston stroke length at reference and nonreference conditions, respectively.
Dimensions

$\mathrm{F} / \mathrm{L}^{2}$

$\mathrm{F} / \mathrm{L}^{2}$

$\mathrm{F} / \mathrm{L}^{2}$

pulses/t

pulses/t

pulses/L

pulses $/ \mathrm{L}^{3}$

pulses $/ \mathbf{L}^{3}$

pulses $/ \mathbf{L}^{3}$

L 


\begin{tabular}{|c|c|c|c|c|c|}
\hline$N_{\mathrm{E} 0}, N_{\mathrm{E}}$ & Totalized encoder pulses & pulses & $t$ & Time. & $\mathbf{t}$ \\
\hline & $\begin{array}{l}\text { at reference and non- } \\
\text { reference conditions, } \\
\text { respectively. }\end{array}$ & & $T_{\text {COLL'T }}$ & $\begin{array}{l}\text { Temperature of fluid } \\
\text { in collection vessel. }\end{array}$ & ${ }^{\circ} \mathrm{C}\left({ }^{\circ} \mathrm{F}\right)$ \\
\hline$N_{\mathrm{M} 0}, N_{\mathrm{M}}$ & $\begin{array}{l}\text { Totalized meter pulses at } \\
\text { reference and non- } \\
\text { reference conditions, } \\
\text { respectively. }\end{array}$ & pulses & $T_{M 0}, T_{M}$ & $\begin{array}{l}\text { Temperature of the } \\
\text { flowmeter at reference } \\
\text { and non-reference } \\
\text { conditions, respectively. }\end{array}$ & ${ }^{\circ} \mathrm{C}\left({ }^{\circ} \mathrm{F}\right)$ \\
\hline$n$ & Unit vector. & dimensionless & $t_{\mathrm{M} 0}$ & Thickness of the body of & $\mathbf{L}$ \\
\hline$P_{\mathrm{co}}, P_{\mathrm{c}}$ & $\begin{array}{l}\text { Pressure of the fluid in } \\
\text { the cylinder of the }\end{array}$ & $\mathrm{F} / \mathrm{L}^{2}$ & & $\begin{array}{l}\text { the flowmeter at reference } \\
\text { conditions. }\end{array}$ & \\
\hline & $\begin{array}{l}\text { calibrator at reference } \\
\text { and non-reference } \\
\text { conditions, respectively. }\end{array}$ & & $U_{\text {M0 }}$ & $\begin{array}{l}\text { Average velocity of fluid } \\
\text { through the flowmeter at } \\
\text { reference conditions. }\end{array}$ & $\mathrm{L} / \mathrm{t}$ \\
\hline$P_{\text {COLL'T }}$ & $\begin{array}{l}\text { Pressure of fluid in } \\
\text { collection vessel. }\end{array}$ & $\mathrm{F} / \mathrm{L}^{2}$ & $V_{c o}, V_{c}$ & $\begin{array}{l}\text { Calibrator piston } \\
\text { displacement at reference }\end{array}$ & $\mathrm{L}^{3}$ \\
\hline$P_{\mathrm{M} 0}, P_{\mathrm{M}}$ & Pressure of the fluid in & $\mathrm{F} / \mathrm{L}^{2}$ & & $\begin{array}{l}\text { and non-reference } \\
\text { conditions, respectively. }\end{array}$ & \\
\hline & and non-reference con- & & $\boldsymbol{v}$ & Fluid velocity vector. & $L / t$ \\
\hline & ditions, respectively. & & $V$ & Control volume. & $\mathrm{L}^{3}$ \\
\hline $\operatorname{Re}$ & Reynolds number. & dimensionless & $\dot{V}_{\boldsymbol{c}}, V_{\boldsymbol{\infty}}$ & Fluid volumetric flowrate & $\mathrm{L}^{3} / \mathrm{t}, \mathrm{L}^{3}$ \\
\hline Ro & Roshko number. & dimensionless & & and volume, respectively, & \\
\hline$S t$ & Strouhal number. Where & dimensionless & & at reference condition. & \\
\hline & $\begin{array}{l}\text { over-bars are used is } \\
\text { meant the average value } \\
\text { over a Reynolds number } \\
\text { range. }\end{array}$ & & $\begin{array}{l}\dot{V}_{\text {COLL'To }} \\
V_{\text {COLL'To }}\end{array}$ & $\begin{array}{l}\text { Fluid volumetric flowrate } \\
\text { and volume, respectively, } \\
\text { into collection vessel at } \\
\text { reference conditions. }\end{array}$ & $\mathrm{L}^{3} / \mathrm{t}, \mathrm{L}^{3}$ \\
\hline$S$ & $\begin{array}{l}\text { Surface area of control } \\
\text { volume. }\end{array}$ & $\mathbf{L}^{2}$ & $\dot{V}_{\mathrm{c}}, V_{\mathrm{c}}$ & $\begin{array}{l}\text { Fluid volumetric flowrate } \\
\text { and volume, respectively, }\end{array}$ & $\mathrm{L}^{3} / \mathrm{t}, \mathrm{L}^{3}$ \\
\hline$T_{\mathrm{r}}$ & $\begin{array}{l}\text { Temperature of meter } \\
\text { rotor or of rod connected } \\
\text { to calibrator piston. }\end{array}$ & ${ }^{\circ} \mathrm{C}\left({ }^{\circ} \mathrm{F}\right)$ & & $\begin{array}{l}\text { in the calibrator cylinder } \\
\text { at non-reference } \\
\text { conditions. }\end{array}$ & \\
\hline$T_{\mathrm{co}}, T_{\mathrm{C}}$ & $\begin{array}{l}\text { Temperature of the } \\
\text { cylinder of the calibrator } \\
\text { at reference and non- } \\
\text { reference conditions, }\end{array}$ & ${ }^{\circ} \mathrm{C}\left({ }^{\circ} \mathrm{F}\right)$ & $\dot{V}_{\mathrm{M} 0}, V_{\mathrm{M} 0}$ & $\begin{array}{l}\text { Fluid volumetric flowrate } \\
\text { and volume, respectively, } \\
\text { in flowmeter at reference } \\
\text { conditions. }\end{array}$ & $\mathrm{L}^{3} / \mathrm{t}, \mathrm{L}^{3}$ \\
\hline & respectively. & & $\dot{V}_{\mathrm{M}}, V_{\mathrm{M}}$ & Fluid volumetric flowrate & $\mathrm{L}^{3} / \mathrm{t}, \mathrm{L}^{3}$ \\
\hline$T_{\mathrm{E} 0}, T_{\mathrm{E}}$ & $\begin{array}{l}\text { Temperature of the } \\
\text { encoder at reference } \\
\text { and non-reference } \\
\text { conditions, respectively. }\end{array}$ & ${ }^{\circ} \mathrm{C}\left({ }^{\circ} \mathrm{F}\right)$ & & $\begin{array}{l}\text { and volume, respectively, } \\
\text { through the flowmeter } \\
\text { at non-reference } \\
\text { conditions. }\end{array}$ & \\
\hline$t_{\mathbf{c o}}$ & $\begin{array}{l}\text { Thickness of the cylinder } \\
\text { of the calibrator at } \\
\text { reference conditions. }\end{array}$ & $\mathbf{L}$ & $\alpha_{\mathrm{E}}$ & $\begin{array}{l}\text { Linear expansion coef- } \\
\text { of the encoder at } \\
\text { pertinent conditions. }\end{array}$ & ${ }^{\circ} \mathrm{C}^{-1}\left({ }^{\circ} \mathrm{F}^{-1}\right)$ \\
\hline$t_{\mathrm{T} 0}$ & $\begin{array}{l}\text { Thickness of the tube } \\
\text { connected to the to the } \\
\text { calibrator piston at } \\
\text { reference conditions. }\end{array}$ & $\mathbf{L}$ & $\alpha_{C}$ & $\begin{array}{l}\text { Linear expansion coef- } \\
\text { ficient for the material } \\
\text { of the calibrator cylinder } \\
\text { at pertinent conditions. }\end{array}$ & ${ }^{\circ} \mathrm{C}^{-1}\left({ }^{\circ} \mathrm{F}^{-1}\right)$ \\
\hline
\end{tabular}




\begin{tabular}{|c|c|c|}
\hline$\alpha_{F}$ & $\begin{array}{l}\text { Linear expansion } \\
\text { coefficient of fluid. }\end{array}$ & ${ }^{\circ} \mathrm{C}^{-1}\left({ }^{\circ} \mathrm{F}^{-1}\right)$ \\
\hline$\alpha_{M}$ & $\begin{array}{l}\text { Linear expansion } \\
\text { coefficient for the } \\
\text { material of the body } \\
\text { of the flowmeter. }\end{array}$ & ${ }^{\circ} \mathrm{C}^{-1}\left({ }^{\circ} \mathrm{F}^{-1}\right)$ \\
\hline$\alpha_{\mathrm{r}}$ & $\begin{array}{l}\text { Linear expansion } \\
\text { coefficient for the } \\
\text { material of rotor or } \\
\text { turbine wheel. }\end{array}$ & ${ }^{\circ} \mathrm{C}^{-1}\left({ }^{\circ} \mathrm{F}^{-1}\right)$ \\
\hline$\beta$ & $\begin{array}{l}\text { Ratio of turbine } \\
\text { propeller diameter to } \\
\text { inside diameter of meter. }\end{array}$ & dimensionless \\
\hline$\epsilon_{\theta}$ & $\begin{array}{l}\text { Hoop strain in cylindrical } \\
\text { body. }\end{array}$ & dimensionless \\
\hline$\rho$ & Fluid density. & $\mathrm{M} / \mathrm{L}^{3}$ \\
\hline$\rho_{\mathrm{CO}}, \rho_{\mathrm{C}}$ & $\begin{array}{l}\text { Fluid density in calibrator } \\
\text { at reference and non- } \\
\text { reference conditions, } \\
\text { respectively. }\end{array}$ & $M / L^{3}$ \\
\hline $\begin{array}{l}\rho_{\text {COLL'To }} \\
\rho_{\text {COLLT }}\end{array}$ & $\begin{array}{l}\text { Density of fluid collected } \\
\text { in collection vessel at } \\
\text { reference and non- } \\
\text { reference conditions, } \\
\text { respectively. }\end{array}$ & $\mathrm{M} / \mathrm{L}^{3}$ \\
\hline$\rho_{M 0}, \rho_{M}$ & $\begin{array}{l}\text { Density of the fluid in the } \\
\text { flowmeter at reference } \\
\text { and non-reference } \\
\text { conditions, respectively. }\end{array}$ & $\mathrm{M} / \mathrm{L}^{3}$ \\
\hline$\sigma_{\theta}$ & $\begin{array}{l}\text { Hoop stress in cylindrical } \\
\text { body. }\end{array}$ & $\mathrm{F} / \mathrm{L}^{2}$ \\
\hline$\nu_{0}, \nu$ & $\begin{array}{l}\text { Fluid kinematic viscosity } \\
\text { at reference and non- } \\
\text { reference conditions, } \\
\text { respectively. }\end{array}$ & $L^{2} / t$ \\
\hline$\mu_{0}, \mu$ & $\begin{array}{l}\text { Fluid absolute viscosity } \\
\text { at reference and non- } \\
\text { reference conditions, } \\
\text { respectively. }\end{array}$ & $\mathrm{Ft} / \mathrm{L}^{2}$ \\
\hline
\end{tabular}

\section{Introduction}

Fluid flowmeter calibration methods use a variety of techniques; they include wide ranges of operational parameters; they cover wide ranges of precision and accuracy, [1-3]. Increasingly, the diverse improvements being sought for flowmeters are producing corresponding improvements in the characteristics of flowmeter calibration systems. Of these systems, the piston displacement-type calibrator offers advantages such as compactness, mobility, efficient change of fluid, and prospects for state-of-the-art performance characteristics.

To characterize the performance of a piston displacement calibrator, which produces a pulsed output signal that is proportional to the volumetric flowrate, the objective is, generally, to determine the "pulses per volume displacement" ratio (or its reciprocal) where the pulse output is assumed to come from a source such as a linear encoder. This pulse output is also assumed to be proportional to the piston displacement. High accuracy calibrator performance requires examination of these assumptions.

A number of techniques can be used to determine volumetric displacement. It is assumed in what follows that the displaced fluid is a liquid, but the principles apply to gases or mixtures of gases and liquids as well. It is also assumed that both temperature and pressure effects on all the components of the piston displacement system, the cylinder, encoder, and fluid should be considered in order that high accuracy performance can be achieved.

Depending upon the desired uncertainty level for the performance of the calibrator, one or more of the pressure and temperature effects on the components of the system may be negligible. When this is so, it may be permissible to disregard such effects to simplify data processing or to reduce the size of the controlling software for the system. Alternatively, and more preferably, all effects can be included in computer software. In this way, the terms which are negligible will not influence the results when higher levels of uncertainty, i.e., less precise performance can be tolerated or is desirable from benefits vs. costs perspectives. More importantly, where high accuracy is required, more of the figures available via the software capabilities can be accepted as significant.

The volumetric-type calibrator system, using encoded piston displacement as both the flow source and as the flow determination scheme, is sketched in Fig. 1. The piston motion produces and measures a fluid volumetric flowrate that is proportional to the encoder frequency. The piston in the cylinder has a seal that is assumed to seal perfectly for all piston velocities. The corresponding fluid flowrate through the meter and the meter output frequency enable a calibration of the flowmeter. Using these elements, three steps are considered. 


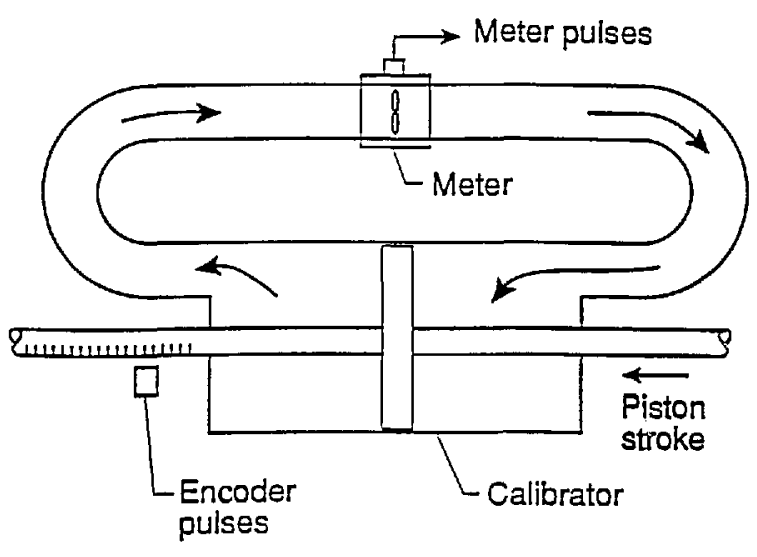

Fig. 1. Sketch of encoded-stroke calibrator in operation.

The first step is determining the calibrator factor which is an "encoder pulses per volume displaced" ratio (or its reciprocal) at the defined set of reference conditions. These results can be obtained experimentally in a number of ways: (1) by physical measurement, (2) by the so-called "draw" technique, or (3) by using a transfer standard such as a single or, preferably, a tandem arrangement of calibrated turbine flowmeters.

The second step is the use of the characterized calibrator to calibrate a pulsed-output flowmeter such as a turbine meter or other device where the meter factor is a "pulses per volume" quantity or its reciprocal. This process is done with one or more selected fluids and at specified conditions. In what follows turbine flowmeters will be considered. Conventionally, turbine meter results are produced in the form of a meter factor which has units of pulses per volume or volume per pulses (referenced to specified conditions). This meter factor is determined over the desired ranges of fluid conditions and flowrate expressed in terms of a ratio of inertial-to-viscous effects such as a Reynolds number, or equivalent parameter.

The third step is the use of the characterized turbine flowmeter to calculate a fluid flowrate under actual conditions of use. The results can be produced with respect to specified reference conditions or to the actual conditions, depending upon the needs of the meter operator.

The purpose of this paper is to describe these three steps and give the pertinent relationships that pertain to each procedure. The resulting equations are intended to be used in the software packages used with these types of calibrators and metering units. In this way, it is expected that the measurement performance of both the calibrators and the metering units can be maximized.

\section{Calibrator Characterization}

\subsection{Geometrical Determination at Reference Conditions}

To perform the required measurements at reference conditions and then calculate the calibrator factor in units of pulses per fluid volume displaced, the system analyzed is that sketched in Fig. 2. The assumption of reference conditions is a conceptual situation that is impractical to achieve precisely but is done solely for convenience, as will be clear in what follows. For the conditions selected to be the reference conditions which are denoted by the " 0 " subscript, a specific piston stroke produces a displacement volume, $V_{\mathrm{CO}}$, and the encoder produces the corresponding number of pulses, $N_{\mathrm{E} 0}$. A list of symbols is given in the Glossary. The reference conditions of calibrator temperature and the pressure in the calibrator are $T_{\mathrm{Co}}$ and $P_{\mathrm{CO}}$, respectively. These properties are assumed to be constant and steady in the calibrator volume. These conditions should be monitored, quantified, and assessed with respect to the performance level of the calibrator. Furthermore, the fluid inside and outside the calibrator is assumed to have the same temperature as the cylinder of the calibrator and no heat is being transferred to or from the calibrator. In all that follows, the reference conditions of $T_{0}$ and $P_{0}$ will be assumed to be the same for all components.

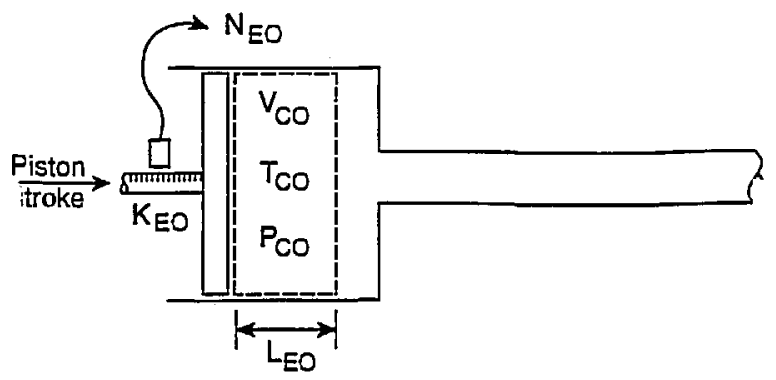

Fig. 2. Encoded-stroke calibrator configuration at reference conditions.

The specified piston stroke, $L_{\mathrm{E} 0}$, produces the pulse total, $N_{\mathrm{E} 0}$, where

$$
N_{\mathrm{E} 0}=L_{\mathrm{E} 0} K_{\mathrm{E} 0} \text {, }
$$

and $K_{\mathrm{E} 0}$ is the encoder constant in pulses per length at the reference temperature condition, $T_{0}$. The calibration constant can be written

$$
K_{\mathrm{CO}}=\frac{N_{\mathrm{E} 0}}{V_{\mathrm{CO}}}=\frac{L_{\mathrm{E} 0} K_{\mathrm{E} 0}}{\bar{A}_{\mathrm{C} 0} L_{\mathrm{E} 0}}=\frac{K_{\mathrm{E} 0}}{\bar{A}_{\mathrm{C}}}
$$


in units of pulses per volume, where, at the reference conditions, $\bar{A}_{\mathrm{co}}$ is the averaged cylinder crosssectional area over the piston stroke, $L_{\mathrm{E} 0}$. This calibrator constant, $K_{\mathrm{CO}}$ is assumed to be constant over the operating range of the calibrator.

For the calibrator configuration shown in Fig. 1, the area $\bar{A}_{\mathrm{Co}}$ is an annular one between the cylinder of the calibrator and the rod or tube attached to the piston. The precision with which $K_{\mathrm{co}}$ is determined can be written using root-sumsquare combinations of component precisions:

$$
\begin{aligned}
\frac{\Delta K_{\mathrm{C} 0}}{K_{\mathrm{C} 0}} & <\left[\left(\frac{\Delta N_{\mathrm{E} 0}}{N_{\mathrm{E} 0}}\right)^{2}+\left(\frac{\Delta V_{\mathrm{CO}}}{V_{\mathrm{C} 0}}\right)^{2}\right]^{1 / 2} \\
& =\left[\left(\frac{\Delta K_{\mathrm{E} 0}}{K_{\mathrm{E} 0}}\right)^{2}+\left(\frac{\Delta \bar{A}_{\mathrm{CO}}}{\bar{A}_{\mathrm{C} 0}}\right)^{2}\right]^{1 / 2},
\end{aligned}
$$

where the numerators of the respective terms refer to the maximum errors of each of the component measurements. Equation (3) indicates that high levels of precision in $K_{\mathrm{co}}$ can be attained when large pulse sums, $N_{\mathrm{E} 0}$, and large displaced volumes, $V_{\mathrm{co}}$, are used. Correspondingly, these precision levels can be achieved with accurate and sensitive linear encoders and accurately measured and large cross-sectional areas.

\subsection{Geometrical Determination at Non-Reference Conditions}

To perform the required measurements at nonreference temperature and pressure conditions, it is assumed that these conditions are constant and steady as shown in Fig. 3. For a specified piston stroke, $L_{\mathrm{E}}$, the corresponding encoder pulse total, $N_{\mathrm{E}}$, is

$$
N_{\mathrm{E}}=L_{\mathrm{E}} K_{\mathrm{E}},
$$

where the encoder constant, $K_{\mathrm{E}}$, is assumed to depend only on temperature according to

$$
K_{\mathrm{E}}=K_{\mathrm{E} 0}\left[1-\alpha_{\mathrm{E}}\left(T_{\mathrm{E}}-T_{\mathrm{E} 0}\right)\right.
$$

where $\alpha_{E}$ is the pertinent linear expansion coefficient for the encoder and $T_{\mathrm{E}}$ and $T_{\mathrm{E} o}$ are, respectively, the encoder temperatures at non-reference and reference conditions.

The cross-sectional area change of the calibrator cylinder that is produced by temperature, $T_{\mathrm{C}}$, and internal fluid pressure, $P_{\mathrm{c}}$, in excess of the reference values is analyzed in Appendix A. In what follows, it is assumed that the annular area contained between the calibrator cylinder and the rod or tube connected to the piston is changed with temperature in the usual way and the pressure effect is considered to enlarge only the cylinder of the calibrator. The pressure effect on the tube or rod is taken to be negligible. The cross-sectional area of the cylinder of the calibrator averaged over the stroke length is given, to first order in temperature and pressure separately, by

$$
\bar{A}_{\mathrm{C}}=\bar{A}_{\mathrm{co}}\left[1+2 \alpha_{\mathrm{C}}\left(T_{\mathrm{C}}-T_{0}\right)\right]\left[1+\frac{\left(P_{\mathrm{C}}-P_{0}\right) D_{\mathrm{C} 0}}{t_{\mathrm{co}} E_{\mathrm{C}}}\right]
$$

where $\alpha_{c}$ is the linear expansion coefficient for the material of the calibrator cylinder, $D_{\mathrm{co}}$ and $t_{\mathrm{Co}}$ are, respectively, the inside diameter and wall thickness of the calibrator cylinder at reference conditions and $E_{\mathrm{C}}$ is the modulus of elasticity of the material of the calibrator cylinder. In Eq. (6) the compressive effects of the pressure in the cylinder on the rod attached to the piston are assumed negligible.

If it is assumed that the linear expansion coefficient of the cylinder material is $2 \times 10^{-5}{ }^{\circ} \mathrm{C}^{-1}$, a systematic temperature difference of only $2.5^{\circ} \mathrm{C}$ would produce a corresponding systematic error of $\pm 0.01 \%$ in the calibrator area. Similarly, if it is assumed that the modulus of elasticity for the calibrator material is $2 \times 10^{11} \mathrm{~Pa}\left(2 \times 10^{6} \mathrm{~atm}\right)$ and if the calibrator has a diameter to thickness ratio of 20 , a systematic pressure error of only $1 \mathrm{MPa}(10 \mathrm{~atm})$ will produce a systematic error of $\pm 0.01 \%$ in the calibrator area. Such calibrator area errors will propagate through all of the successive relationships for calibrating and using meters, and these relationships will be further altered by additional temperature and pressure effects.

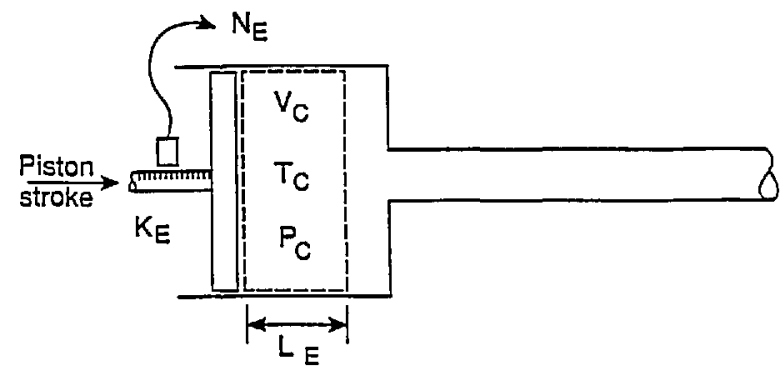

Fig. 3. Encoded-stroke calibrator configuration at non-reference conditions. 
The calibrator constant, $K_{\mathrm{C}}$, at non-reference conditions in units of pulses per volume can be written

$$
K_{\mathrm{C}}=\frac{N_{\mathrm{E}}}{V_{\mathrm{C}}}
$$

since $V_{\mathrm{C}}$ is the displacement at non-reference conditions. Therefore

$$
K_{\mathrm{C}}=\frac{K_{\mathrm{E}}}{\bar{A}_{\mathrm{C}}}
$$

Combining Eq. (8) with Eqs. (2), (5), and (6) produces

$$
K_{\mathrm{C}}=\frac{K_{\mathrm{C} 0}\left[1-\alpha_{\mathrm{E}}\left(T_{\mathrm{E}}-T_{0}\right)\right]}{\left[1+2 \alpha_{\mathrm{C}}\left(T_{\mathrm{C}}-T_{0}\right]\left[1+\frac{\left(P_{\mathrm{C}}-P_{0}\right) D_{\mathrm{C} 0}}{t_{\mathrm{C} 0} E_{\mathrm{C}}}\right]\right.},
$$

or, to first order approximation:

$$
K_{\mathrm{C} 0}=K_{\mathrm{C}} \frac{\left[1+\alpha_{\mathrm{E}}\left(T_{\mathrm{E}}-T_{0}\right)\right]}{\left[1-2 \alpha_{\mathrm{C}}\left(T_{\mathrm{C}}-T_{0}\right]\left[1-\frac{\left(P_{\mathrm{C}}-P_{0}\right) D_{\mathrm{CO}}}{t_{\mathrm{CO}} E_{\mathrm{C}}}\right]\right.}
$$

For temperatures and pressures higher than reference conditions the calibrator constant, $K_{\mathrm{c}}$, is less than the value at reference conditions. In both of the above geometrical methods for obtaining calibrator constants, fluid properties are not involved.

The value for $K_{c o}$ given by Eqs. (2) or (10) should be put into the software that operates the displacement calibrator, together with pertinent material constants and component dimensions. Then the computation for the calibrator constant $K_{\mathrm{C}}$ at non-reference conditions can be done using appropriate measurements for encoder temperature, in addition to the pressure and temperature in the calibrator, as shown in Eq. (9). These values of $K_{\mathrm{Co}}$ or $K_{\mathrm{C}}$ will be used for the accurate calibrations of flowmeters.

\subsection{Determination of Calibrator Constant by the Draw Technique at Reference Conditions}

The configuration for the draw technique is shown in Fig. 4, where the piston stroke displaces an amount of fluid through a valve into the collection tank; the corresponding encoder pulses total $\mathrm{N}_{\mathrm{EO}}$. All temperatures and pressures are the reference values. In all that follows, it is assumed that the seal of the piston in the calibrator seals perfectly and is sufficiently pliant to continue to seal perfectly when changes in temperature and internal pressure occur and change the diameter of the cylinder of the calibrator. Applying conservation of mass principles to the constant volume shown in figure 4, we obtain:

$$
\frac{\partial}{\partial t} \int_{V} \rho \mathrm{d} V-\int_{S} \rho v \cdot n \mathrm{~d} S=0,
$$

where $\rho$ is the fluid density, $V$ is the control volume surrounded by the control surface, $S, \boldsymbol{v}$ is the fluid velocity vector, and $n$ is the unit vector normal to $S$ with positive direction pointing to the interior of $V$. When

$$
\frac{\partial}{\partial t} \int_{V} \rho \mathrm{d} V=0
$$

there is no change of the mass within the control volume in time. This means the effects of fluid friction or of heat transfer are negligible or, taken in total, do not alter in time the mass contained within the control volume. Under such conditions, the inlet and outlet mass fluxes through the control surface, $S$ are the same, that is

$$
\rho_{\mathrm{CO}} \dot{V}_{\mathrm{CO}}=\rho_{\mathrm{COLL} \cdot \mathrm{TO}} \dot{V}_{\mathrm{COLL}} \mathrm{To},
$$

where $\rho_{\mathrm{CO}}$ and $\rho_{\text {coll } \mathrm{wo}}$ are the fluid densities, respectively, in the calibrator and collection tank at the same reference conditions and therefore are equal. The quantities $\dot{V}_{\mathrm{Co}}$ and $\dot{V}_{\text {CoLL' }}$ are the volumetric flowrates out of the calibrator and into the collection tank, respectively.

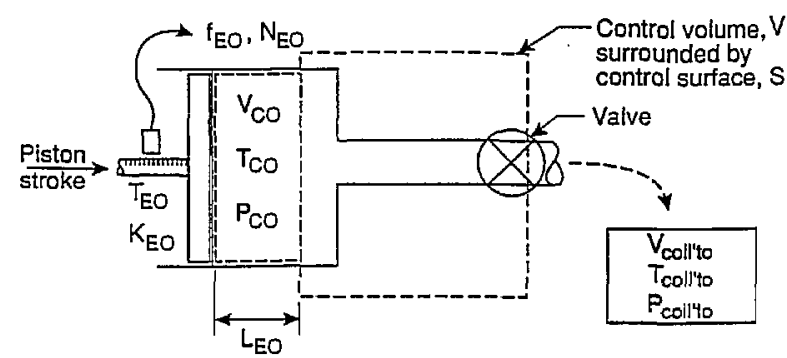

Fig. 4. Experimental arrangement for the draw technique at reference conditions.

Therefore, since the times of displacement and collection are assumed to be the same,

$$
V_{\mathrm{CU}}=V_{\text {COLL'TO }}
$$


and the calibrator constant, in units of pulses per displacement volume can be written

$$
K_{\varnothing 0}=N_{\text {EO }} / V_{\text {COLLTo }}
$$

where

$$
V_{\text {COLL'T }}=\bar{A}_{\mathrm{CO}} L_{\mathrm{E} 0} .
$$

Therefore, using Eq. (13)-(16), we obtain

$$
K_{\mathrm{CO}}=K_{\mathrm{EO}} / \bar{A}_{\mathrm{CO}},
$$

in agreement with Eq. (2). Accordingly, results obtained via this procedure should duplicate those obtained via the geometrical measurement techniques.

It is generally assumed that the calibrator constant $K_{\mathrm{CO}}$ is independent of the piston speed or the fluid properties. If this assumption is not valid then it is necessary to characterize the dependence. This should be done in a manner analogous to the procedures used to characterize turbine meters as given below.

It should be noted that, for the control volume shown in Fig. 4, if

$$
\frac{\partial}{\partial t} \int_{V} \rho \mathrm{d} V \neq 0
$$

then the mass flux displaced in the cylinder of the calibrator is not equal to that delivered to the collection tank. Furthermore, if the fluid density in the control volume decreases because of a temperature rise then the mass flux to the collection tank would be more than that displaced in the calibrator cylinder. As will be seen below, this produces a turbine-type meter calibration result in pulses per volume units that is larger than it should be. Conversely, if the fluid density in the control volume increases, then the mass flux delivered to the collection vessel is less than that displaced in the calibrator cylinder. This produces a low calibration result for a turbine meter constant in pulses per volume units.

\subsection{Determination of Calibrator Constant by the Draw Technique at Non-Reference Conditions}

The configuration for the draw technique in nonreference conditions is shown in Fig. 5. As before, the piston stroke displaces a volume of fluid in the cylinder and the corresponding encoder pulses total $N_{\mathrm{E}}$. The temperature and pressure of the fluid in the cylinder are $T_{\mathrm{C}}$ and $P_{\mathrm{C}}$, respectively. Apply-

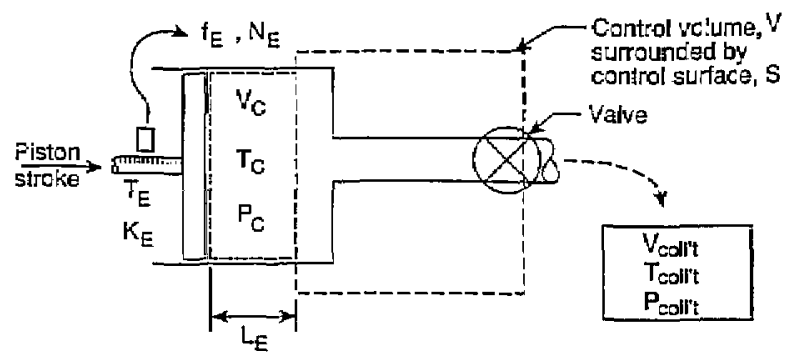

Fig. 5. Experimental arrangement for the draw technique at non-reference conditions.

ing conservation of mass principles to the control volume in Fig. 5, for the condition where there is no change with time of the mass within the control volume, Eq. (11) and (12) indicate that

$$
\rho_{\mathrm{C}} \dot{V}_{\mathrm{C}}=\rho_{\mathrm{COLL}} \dot{\mathrm{V}}_{\mathrm{COLL} \mathrm{T}}
$$

or when the displacement and collected volumes are simultaneous

$$
\rho_{\mathrm{C}} V_{\mathrm{C}}=\rho_{\text {COLL'T }} V_{\text {COLL'T }}
$$

where $\rho_{\mathrm{C}}$ and $\rho_{\text {coL'T }}$ are, respectively, the density of the fluid displaced within the cylinder of the calibrator and flowing from the valve and into the collection tank. The volume $V_{\text {CoLl'T }}$ can be determined using volumetric or gravimetric techniques, or both. It is noted that constant conditions of temperature and pressure need to be maintained in the calibrator and in the collection vessel for accurate results.

With the volume $V_{\text {CoLL'T }}$ determined, $V_{C}$ can be computed via

$$
V_{\mathrm{C}}=\left(\rho_{\text {COLL'T }} / \rho_{\mathrm{C}}\right) V_{\text {COLL'T }},
$$

where, according to the definitions of fluid thermal expansion effects and compressibility, to first order in temperature and pressure, separately:

$$
\begin{aligned}
& \frac{\rho_{\text {COLLTT }}}{\rho_{\mathrm{C}}}= \\
& {\left[1-3 \alpha_{\mathrm{F}}\left(T_{\text {COLL'T }}-T_{\mathrm{C}}\right)\right]\left[1+\frac{\left(P_{\text {COLL'T }}-P_{\mathrm{C}}\right)}{E_{\mathrm{F}}}\right],}
\end{aligned}
$$

where $\alpha_{\mathrm{F}}$ is the linear expansion coefficient for the fluid, the pressures $P_{\text {coll't }}$ and $P_{\mathrm{C}}$ are, respectively, those for the fluid passing from the valve into the collection tank and in the cylinder of the calibrator, and $E_{\mathrm{F}}$ is the modulus of elasticity of the fluid. It is noted that both $\alpha_{F}$ and $E_{F}$ are dependent upon temperature and pressure for the specific fluid, but 
the values used here and in what follows are assumed to be averages taken over the appropriate ranges of temperature and pressure. It is also noted here that the reciprocal of the modulus of elasticity of the fluid is also the compressibility of the fluid.

In Eq. (22), it is noted that temperature and pressure effects have opposite signs in producing fluid density changes. However, when the temperature differences between the collection vessel and the calibrator are large and where the pressure in the calibrator is much larger than that in the collection vessel, the effects on the fluid can be significant.

If it is assumed that the linear expansion coefficient of a hydrocarbon liquid is $3 \times 10^{-4}{ }^{\circ} \mathrm{C}^{-1}$, a systematic temperature error of only $1{ }^{\circ} \mathrm{C}$ will produce a systematic error of $0.1 \%$ due to temperature in the determination of the calibrator volume by this draw method. Similarly, if it is assumed that the fluid's modulus of elasticity is $2 \times 10^{9} \mathrm{~Pa}\left(2 \times 10^{4}\right.$ atm), a systematic pressure error of only $2 \mathrm{MPa}$ $(20 \mathrm{~atm})$ will produce a systematic error of $\pm 0.1 \%$ in the calibrator volume. As mentioned above, such errors will propagate through all of the relationships for calibrating and using meters and these errors will be further altered by additional temperature and pressure corrections.

Furthermore, using Eq. (7) we can write

$$
K_{\mathrm{C}}=\frac{N_{\mathrm{E}}}{\left(\frac{\rho_{\text {CoLL'T }}}{\rho_{\mathrm{C}}}\right) V_{\mathrm{COLL}} \mathrm{T}},
$$

then, from Eq. (22)

$$
\begin{aligned}
K_{\mathrm{C}} & =\frac{N_{\mathrm{E}}}{V_{\text {COLLT }}}\left[1+3 \alpha_{\mathrm{F}}\left(T_{\text {COLLT }}-T_{\mathrm{C}}\right)\right] \\
& \times\left[1-\frac{\left(P_{\text {COLLT }}-P_{\mathrm{C}}\right)}{E_{\mathrm{F}}}\right] .
\end{aligned}
$$

This result is then related to reference conditions via Eq. (10) to give

$$
K_{\mathrm{CU}}=\frac{N_{\mathrm{E}}\left[1+3 \alpha_{\mathrm{F}}\left(T_{\mathrm{COL}} \mathrm{T}-T_{\mathrm{C}}\right)\right]\left[1-\frac{\left(P_{\mathrm{COLLT}}-P_{\mathrm{C}}\right)}{E_{\mathrm{F}}}\right]\left[1+\alpha_{\mathrm{E}}\left(T_{\mathrm{E}}-T_{0}\right)\right]}{V_{\text {COLLT }}\left[1-2 \alpha_{\mathrm{C}}\left(T_{\mathrm{C}}-T_{0}\right)\right]\left[1-\frac{\left(P_{\mathrm{C}}-P_{0}\right) D_{\mathrm{CO}}}{T_{\mathrm{CO}} E_{\mathrm{C}}}\right] .}
$$

It is noted that the cross-sectional area, $\bar{A}_{\mathrm{C}}$ can be determined via Eqs. (8) and (23) to be

$$
\bar{A}_{\mathrm{C}}=\frac{K_{\mathrm{E}}}{N_{\mathrm{E}}}\left(\frac{\rho_{\text {COLLT }}}{\rho_{\mathrm{C}}}\right) V_{\text {COL'T }} .
$$

Using Eqs. (5), (6) and (22), this can be written in terms of directly measured quantities and related to reference conditions via

$$
\begin{aligned}
& \bar{A}_{\mathbf{C O}}= \\
& K_{\mathrm{E} 0} V_{\mathrm{COLLT}}\left[1-\alpha_{\mathrm{E}}\left(T_{\mathrm{E}}-T_{0}\right)\right]\left[1-2 \alpha_{\mathrm{C}}\left(T_{\mathrm{C}}-T_{0}\right)\right]\left[1-\frac{\left(P_{\mathrm{C}}-P_{0}\right) D_{\mathrm{CO}}}{l_{\mathrm{CO}} E_{\mathrm{C}}}\right] \\
& N_{\mathrm{E}}\left[1+3 \alpha_{\mathrm{F}}\left(T_{\text {coul }} \cdot \mathrm{T}-T_{\mathrm{C}}\right)\right]\left[1-\frac{\left(P_{\text {coul } \mathrm{T}}-P_{\mathrm{C}}\right)}{E_{\mathrm{F}}}\right] \text {. }
\end{aligned}
$$

If $K_{\mathrm{C}}^{\prime}$ is defined as

$$
K_{\mathrm{C}}^{\prime}=N_{\mathrm{E}} / V_{\text {COLL'T }} \text {, }
$$

then

$$
\frac{K_{\mathrm{CO}}=K_{\mathrm{C}}^{\prime} \times}{\left[1+2 \alpha_{\mathrm{C}}\left(T_{\mathrm{C}}-T_{\mathrm{o}}\right)\right]\left[1+\frac{\left(P_{\mathrm{C}}-P_{0}\right) D_{\mathrm{C}}}{t_{\mathrm{CO}} E_{\mathrm{C}}}\right]}
$$

or, to first order

$$
\begin{aligned}
& K_{\mathrm{C}}^{\prime}=K_{\mathrm{OO}} \mathrm{X} \\
& \frac{\left[1-2 \alpha_{\mathrm{C}}\left(T_{\mathrm{C}}-T_{0}\right)\right]\left[1-\frac{\left(P_{\mathrm{C}}-P_{0}\right) D_{\mathrm{C}}}{t_{\mathrm{CO}} E_{\mathrm{C}}}\right]}{\left[1+3 \alpha_{\mathrm{F}}\left(T_{\mathrm{COL} \cdot \mathrm{T}}-T_{\mathrm{C}}\right)\right]\left[1-\frac{\left(P_{\mathrm{COL} \cdot \mathrm{T}}-P_{\mathrm{C}}\right)}{E_{\mathrm{F}}}\right]\left[1+\alpha_{\mathrm{E}}\left(T_{\mathrm{E}}-T_{\mathrm{D}}\right)\right]} .
\end{aligned}
$$

When temperatures exceed those of the reference conditions and pressures are those for the reference conditions:

$$
K_{\mathrm{C}}^{\prime}<K_{\mathrm{Co}} \text {. }
$$

Thus, the observation made above is repeated here, namely, that when pressure effects can be neglected and when temperatures are above the reference conditions, the calibrator delivers, for the same encoder output pulses, more fluid volume than would occur under reference conditions. 
It is also noted that Eqs. (23)-(27) can be combined to give:

$$
K_{\mathrm{C}}=K_{\mathrm{C} 0} \frac{\left[1-\alpha_{\mathrm{E}}\left(T_{\mathrm{E}}-T_{0}\right)\right]}{\left[1+2 \alpha_{\mathrm{C}}\left(T_{\mathrm{C}}-T_{0}\right]\left[1+\frac{\left(P_{\mathrm{C}}-P_{0}\right) D_{\mathrm{C}}}{t_{\mathrm{CO}} E_{\mathrm{C}}}\right]\right.}
$$

which is the same as Eq. (9).

It is noted that, in these two draw procedures, the decision to collect a sufficiently large number of encoder pulses should precede the operation. This number should be selected according to the desired precision for the calibrator constant, see Eq. (3). In the reference conditions

$$
N_{\mathrm{E} 0}=K_{\mathrm{E} 0} L_{\mathrm{E} 0},
$$

and in the non-reference conditions

$$
N_{\mathrm{E}}=K_{\mathrm{E}} L_{\mathrm{E}} \text {, }
$$

but, to first order in temperature,

$$
K_{\mathrm{E}}=K_{\mathrm{ED}}\left[1-\alpha_{\mathrm{E}}\left(T_{\mathrm{E}}-T_{0}\right)\right],
$$

and

$$
L_{\mathrm{E}}=L_{\mathrm{E} 0}\left[1+\alpha_{\mathrm{E}}\left(T_{\mathrm{E}}-T_{0}\right)\right]
$$

Combining Eqs. (33) $-(36)$ therefore yields:

$$
N_{\mathrm{E}}=K_{\mathrm{E}} L_{\mathrm{E}}=K_{\mathrm{E} 0} L_{\mathrm{E} 0}=N_{\mathrm{E} 0} .
$$

This indicates that the precision criterion specified for the calibrator should be achieved via the number of pulses selected and the choice is not dependent upon whether reference or nonreference conditions prevail.

As stated above following equation (17), the calibrator constants determined via the draw procedure are generally assumed to be independent of piston speed and fluid properties. Where this is not valid, efforts should be made to achieve this assumption, i.e., improving the piston seals or the calibrator should be characterized using techniques analogous to those for turbine meters as will be described below.

It should also be noted that in the above described draw procedures, the valve and pulse counting techniques must not introduce spurious effects. Spurious counting effects may result from the fluid dynamics in the valve as the flow is started and stopped in conjunction with starting and stop- ping the pulse count. If such an effect is present then it should be eliminated or proper account made for it so that the appropriate fluid volume is associated with the pulse total. This volume can be determined using the valve compensation techniques that are conventionally applied to diverter systems, see [4].

To use the now-characterized calibrator, it is required that appropriate instrumentation be properly installed both to assure that Eq. (12) is satisfied and to measure the quantities involved in Eqs. (9) or (10) or (32) for the calibrator and equations (28) or (29) or (30) for dispensing precise volumes of fluid at specified conditions of temperature and pressure. Appropriate values are needed for the material constants - the thermal expansion coefficients $\alpha_{\mathrm{E}}, \alpha_{\mathrm{F}}$ and $\alpha_{\mathrm{C}}$, the modulus of elasticity of the material of the calibrator cylinder, $E_{\mathrm{C}}$, and that of the fluid, $E_{F}$, and the pertinent dimensions of the cylinder. Once the appropriate value for the constant $K_{\text {co }}$ has been installed in the calibrator software or the working procedures for the calibrator, the next step is to use the calibrator to calibrate a flowmeter.

\section{Calibrator Use in Calibrating a Turbine Type Flowmeter \\ 3.1 Reference Conditions}

To calibrate a turbine-type flowmeter at reference temperature and pressure conditions using the calibrator characterized as described above, the arrangement is sketched in Fig. 6. The temperature and pressure are the reference conditions denoted by $T_{0}$ and $P_{0}$. As stated above, $T_{0}=T_{\mathrm{M} 0}=T_{\mathrm{Co}}$ and $P_{0}=P_{\mathrm{M} 0}=P_{\mathrm{Co}}$. Applying again the conservation of mass principles, and assuming that there is no change of mass within the control volume with time, Eqs. (11) and (12) indicate that

$$
\rho_{\mathrm{CO}} \dot{V}_{\mathrm{CO}}=\rho_{\mathrm{M} 0} \dot{V}_{\mathrm{MO}}
$$

where $\rho_{\mathrm{CO}}$ and $\rho_{\mathrm{Mo}}$ are the fluid densities in the calibrator and meter, respectively, at the reference conditions. The quantities $\dot{V}_{C 0}$ and $\dot{V}_{\text {Mo }}$ are the volumetric flowrates, respectively, in the calibrator and through the meter at the reference conditions.

Since reference conditions in cylinder and meter are assumed the same, the densities $\rho_{C O}$ and $\rho_{M 0}$ are equal and therefore:

$$
\dot{V}_{\mathrm{CO}}=\dot{V}_{\mathrm{MO}} \text {. }
$$




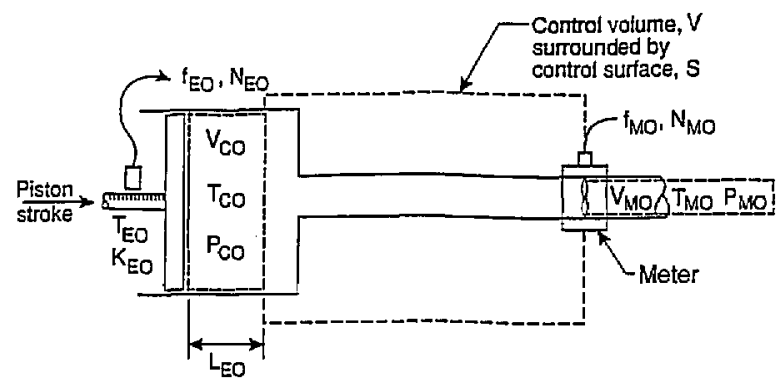

Fig. 6. Arrangement for using characterized calibrator to calibrate a turbine-type flowmeter at reference conditions.

Since the pertinent time intervals are assumed the same:

$$
K_{\mathrm{CO}}=\frac{K_{\mathrm{E} 0}}{\bar{A}_{\mathrm{CO}}}=\frac{N_{\mathrm{EO}}}{\bar{A}_{\mathrm{CO}} L_{\mathrm{E} 0}}=\frac{f_{\mathrm{E} 0}}{\dot{V}_{\mathrm{CO}}},
$$

where $f_{\mathrm{E} O}$ is the encoder frequency, and

$$
K_{\mathrm{M} 0}=\frac{N_{\mathrm{M} 0}}{V_{\mathrm{M} 0}}=\frac{f_{\mathrm{M} 0}}{\dot{V}_{\mathrm{M} 0}}
$$

where $f_{M 0}$ is the meter frequency.

In Eqs. (40) and (41), the pulse counts $N_{\mathrm{EO}}$ and $N_{\mathrm{M} 0}$ are to correspond to the respective volumes $V_{\mathrm{CO}}$ and $V_{\mathrm{M} 0}$ which are assumed to be the same, or appropriate corrections are made to compensate for any differences between these volumes. Combining Eqs. (40) and (41) gives

$$
K_{\mathrm{M} 0}=\frac{f_{\mathrm{M} 0}}{f_{\mathrm{E} 0}} \frac{K_{\mathrm{E} 0}}{\bar{A}_{\mathrm{CO}}}=\frac{N_{\mathrm{M} 0}}{N_{\mathrm{E} 0}} \frac{K_{\mathrm{E} 0}}{\bar{A}_{\mathrm{CO}}}=\frac{N_{\mathrm{M} 0}}{N_{\mathrm{E} 0}} \cdot K_{\mathrm{C} 0}=\frac{f_{\mathrm{M} 0}}{f_{\mathrm{E} 0}} \cdot K_{\mathrm{CO}},
$$

where $K_{\mathrm{M} 0}$ has units of pulses per volume at the reference conditions. The quantity $K_{\mathrm{E} 0}$ is obtained from manufacturer's specifications, testing or Eq. (1).

Conventional non-dimensionalization procedures can be applied to the flowmeter characteristics to produce a set of parameters which interrelate the significant inertial, viscous, and oscillatory effects that constitute the performance of the meter in the calibration conditions, see [6,7]. In this way, the performance of the device can be predicted for other fluid and flow conditions where this set of parameters are the pertinent ones to describe the meter's performance. Of course, when other, different effects such as fluid compressibility or gravitational influences become significant, it should be expected that the initial parameterization needs to be modified to include such effects to obtain satisfactory description of meter performance, see $[8,9]$.
By normalizing the meter factor, $K_{M 0}$ and the fluid flowrate using the meter diameter, $D_{\mathrm{MO}}$ and the mean flow velocity $\dot{V}_{\mathrm{M} 0} / A_{\mathrm{M} 0}=U_{\mathrm{M} 0}$ and the fluid kinematic viscosity $v_{0}$, we can obtain, for example, the Strouhal number

$$
S t=\frac{f_{\mathrm{M} 0} D_{\mathrm{M} 0}}{U \mathrm{M} 0}=C_{1} K_{\mathrm{M} 0} D_{\mathrm{M} 0}^{3} \propto K_{\mathrm{M} 0} D_{\mathrm{M} 0}^{3},
$$

where $C_{1}=\pi / 4$. The Strouhal number is the ratio of characteristic meter frequency effects such as propeller rotation rate to fluid momentum effects. By effects here is meant either forces or energies. As such, the Strouhal number is a dimensionless meter factor.

Conventionally, it is fluid mechanical practice to formulate the Reynolds number as the ratio of fluid inertial to viscous effects,

$$
R e=\frac{D_{M 0} U_{M 0}}{v_{0}}
$$

This is generally used to describe the domain of the meter calibration for which the corresponding Strouhal numbers specify the range of meter response. A Strouhal-Reynolds characterization of a pulse-producing flowmeter conforms to conventional fluid mechanical procedures and it is analogous to orifice metering practice where discharge coefficient (a ratio of fluid inertia to differential pressure effects) is described functionally or graphically versus Reynolds number. However, as noted in Eq. (44) the Reynolds number requires that the fluid velocity be known. Since this is the purpose for using the meter, an iteration technique is required to calculate the flowrate. To avoid such an iteration, turbine meter manufacturers have designed their products to have high levels of linearity over wide flowrate ranges. As a result of this, it has been conventional turbine meter practice to characterize performance via $\boldsymbol{K}$-factor vs. frequency to kinematic viscosity ratio-the so-called Universal Viscosity Curve (UVC). In accord with the principles of dimensional similitude, the meter frequency to fluid viscous effects can be formulated using, as characteristic length scale, the meter diameter, $D_{M 0}$ as in Eq. (44). This formulation can also be achieved via the product of Strouhal and Reynolds numbers; this product has been recently referred to, see [9], as the Roshko number,

$$
R_{0}=\frac{f_{\mathrm{MO}} D_{\mathrm{MO}}^{2}}{v_{0}}
$$


This Roshko number is the dimensionless version of the frequency-to-kinematic viscosity ratio used for the UVC. It is expected that the dimensionless version of the UVC-the StrouhalRoshko characterization - should produce superior prediction of meter performance compared to the UVC by virtue of its more complete, i.e., dimensionless description of the inertial, viscous, and oscillatory effects that occur in the meter operation.

The question of which set of parameters best describes a turbine meter's performance should be determined using appropriate data sets. The specific design considerations of blade size and shape, internal meter geometry, bearing features, etc., can be expected to play significant roles in the selection of non-dimensional parameters. Where it may happen that the Reynolds number produces a better description of turbine meter performance, i.e., the data collapses better onto a single curve than achieved using the Roshko number, an iterative sequence of computations may be necessary to produce an accurate determination of flowrate. If the meter is very linear, such an iteration may not be required. Typical flowmeter characterization results are sketched in Fig. 7. Because it is not known whether Reynolds or Roshko number is the better parameter with which to characterize the meter performance, both shall be included in what follows.

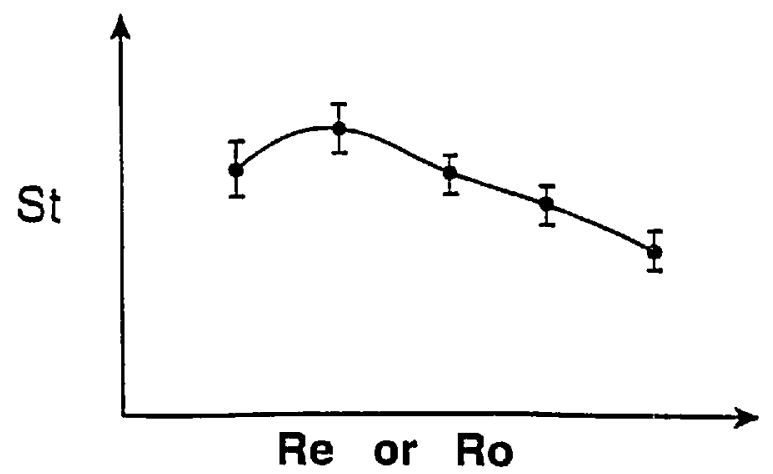

Fig. 7. Normalized calibration results for a turbine-type flowmeter. Points denote averaged results; bars denote standard deviations obtained at each flowrate.

In those instances where meter performance might deviate from the curve shown in Fig. 7, the interpretation would be that additional factors in the deviant conditions have become significant whereas these factors were insignificant in the calibration conditions. Examples might be fluid frictional effects in the turbine bearings produced by extreme viscosity variations from those prevail ing in the calibration conditions, or liquid cavitation effects, etc.

The curve shown in Fig. 7 is interpreted as the functional relationship between the Strouhal and Reynolds or Roshko numbers which are assumed to be the salient parameters describing the performance of this flowmeter over these calibration conditions. Inherent in this interpretation is the assumption that in any subsequent use of this functional relationship, the geometries of this meter, for example, the bearings or the propeller diameter are not changed relative to the selected characteristic length of the meter, i.e., the internal diameter, $D$. If such changes do occur it can be expected that the curve shown in Fig. 7 can change. For example, if a smaller propeller were installed, this curve may retain its shape but lie below that shown in Fig. 7 . A non-dimensional parameter which could take into account different propeller diameters is $\beta=d / D$, where $d$ is the propeller diameter. Accordingly, the curve shown in Fig. 7 would pertain to the specific $\beta$ for which the calibration was done. If other, smaller propellers were also calibrated, these results could be plotted in Fig. 7 and parameterized with the smaller value of $\beta$. When the propeller and meter-body materials are the same and where pressure effects can be neglected, the $\beta$ ratio will remain constant when the temperature changes. When the propeller and the meterbody materials are different, temperature changes can produce different $\beta$ ratios. These different ratios can be computed using pertinent relationships. The computed results should then be used with calibration data taken for different $\beta$ ratios to predict the meter performance at the different temperature conditions, see Appendix B.

Figure 7 is different from conventional turbine meter performance plots in which the meter's $K$-factor is plotted versus the ratio of frequency-tokinematic viscosity. These conventional quantities are different from the Strouhal and Reynolds or Roshko number parameters by constant factors and by factors of the meter diameter raised to different exponents. These powers of the diameter should change only slightly with small changes in temperature and internal pressure. However, when conditions vary widely, the dimensionless formulations should be used and are expected to produce improved meter performance. Plots in the format of Fig. 7 should then, with the exceptions of deviant phenomena becoming influential, apply to a wide range of specific, dimensional fluid property and flow conditions and produce accurate predictions of turbine meter performance. 
Where conventional turbine meter practice is used and plots are produced for $\mathrm{K}$-factor versus the ratio of frequency-to-kinematic viscosity, improved meter performance can be expected when these calibration results are corrected to specified reference conditions. Accordingly, the corrected results should incorporate temperature and internal pressure corrections for the ratios of meter diameters raised to the relevant exponent to predict meter performance for other fluid and flow conditions. For meters having good linearity characteristics, i.e., constancy of the meter factor over specified flowrate ranges, the more important of these two corrections is that for the $K$-factor, i.e.,

$$
K_{M 0}=K_{M}\left(D_{M} / D_{M 0}\right)^{3} .
$$

This stipulates that the meter frequency-to-fluid inertial effects ratio, i.e., Strouhal number be the same in the actual conditions as in the reference conditions. To first order in temperature and pressure, separately, the diametral ratio can be written,

$$
\begin{aligned}
\left(\frac{D_{\mathrm{M}}}{D_{\mathrm{M} 0}}\right)^{3}= & {\left[1+3 \alpha_{\mathrm{M}}\left(T_{\mathrm{M}}-T_{\mathrm{M} 0}\right)\right] } \\
& \times\left[1+\frac{3\left(P_{\mathrm{M}}-P_{\mathrm{M} 0}\right) D_{\mathrm{M} 0}}{2 t_{\mathrm{M} 0} E_{\mathrm{M}}}\right]=\frac{K_{\mathrm{M} 0}}{K_{\mathrm{M}}},
\end{aligned}
$$

where $D_{\mathrm{M}}$ and $D_{\mathrm{M} 0}$ are, respectively, the meter diameters at the non-reference conditions, $T_{M}$ and $P_{M}$ and reference conditions, $T_{M 0}$ and $P_{M 0}$. The quantities $\alpha_{M}$ and $E_{M}$ are, respectively, the linear expansion coefficient and the modulus of elasticity of the meter body material for these conditions, and $t_{\mathrm{M} 0}$ is the thickness of the meter body at reference conditions. The more significant of the two correction factors is usually that for temperature deviations from reference conditions. When the pressure correction can be neglected,

$$
K_{M 0}=K_{M}\left[1+3 \alpha_{M}\left(T_{M}-T_{M 0}\right)\right],
$$

or, to first order:

$$
K_{\mathrm{M}}=K_{\mathrm{M} 0}\left[1-3 \alpha_{\mathrm{M}}\left(T_{\mathrm{M}}-T_{\mathrm{M} 0}\right)\right] .
$$

This relationship duplicates that given in [10].

\subsection{Non-Reference Conditions}

To calibrate a turbine-type flowmeter using the calibrator characterized as described above, the arrangement is sketched in Fig. 8. The temperature and pressure in the calibrator are the nonreference conditions denoted by $T_{\mathrm{C}}$ and $P_{\mathrm{c}}$. Applying again the conservation of mass principles, and assuming that there is no change of mass within the control volume with time, Eq. (11) and (12) indicate that

$$
\rho_{\mathrm{C}} \dot{V}_{\mathrm{C}}=\rho_{\mathrm{M}} \dot{V}_{\mathrm{M}}
$$

Since the fluid conditions in the cylinder and in the meter can be different, the ratio of the densities is

$$
\frac{\rho_{\mathrm{C}}}{\rho_{\mathrm{M}}}=\left[1-3 \alpha_{\mathrm{F}}\left(T_{\mathrm{C}}-T_{\mathrm{M}}\right)\right]\left[1+\frac{P_{\mathrm{C}}-P_{\mathrm{M}}}{E_{\mathrm{F}}}\right]
$$

and from Eq. (32) and in a manner analogous to Eq. (40)

$$
\begin{aligned}
K_{\mathrm{C}}=\frac{K_{\mathrm{E}}}{\bar{A}_{\mathrm{C}}}=\frac{f_{\mathrm{E}}}{\dot{V}_{\mathrm{C}}}= \\
K_{\mathrm{C} 0} \frac{\left[1-\alpha_{\mathrm{E}}\left(T_{\mathrm{E}}-T_{0}\right)\right]}{\left[1+2 \alpha_{\mathrm{C}}\left(T_{\mathrm{C}}-T_{0}\right]\left[1+\frac{\left(P_{\mathrm{C}}-P_{0}\right) D_{\mathrm{C} 0}}{t_{\mathrm{CO}} E_{\mathrm{C}}}\right]\right.}
\end{aligned}
$$

Then, analogously to Eq. (42)

$$
\begin{aligned}
K_{\mathrm{M}}=\frac{f_{M}}{f_{\mathrm{E}}} K_{\mathrm{C}} \frac{\rho_{M}}{\rho_{C}}=\frac{N_{\mathrm{M}}}{N_{\mathrm{E}}} K_{\mathrm{C}} \\
\times \frac{\left[1-\alpha_{\mathrm{E}}\left(T_{\mathrm{E}}-T_{0}\right)\right]\left[1+3 \alpha_{\mathrm{F}}\left(T_{\mathrm{C}}-T_{\mathrm{M}}\right)\right]}{\left[1+2 \alpha_{\mathrm{C}}\left(T_{\mathrm{C}}-T_{0}\right)\right]\left[1+\frac{\left(P_{\mathrm{C}}-P_{0}\right) D_{\mathrm{C}}}{t_{\mathrm{Co}} E_{\mathrm{C}}}\right]\left[1+\frac{\left(P_{\mathrm{C}}-P_{\mathrm{M}}\right)}{E_{\mathrm{F}}}\right]},
\end{aligned}
$$

where $K_{M}$ has units of pulses per volume at the specific, non-reference meter conditions.

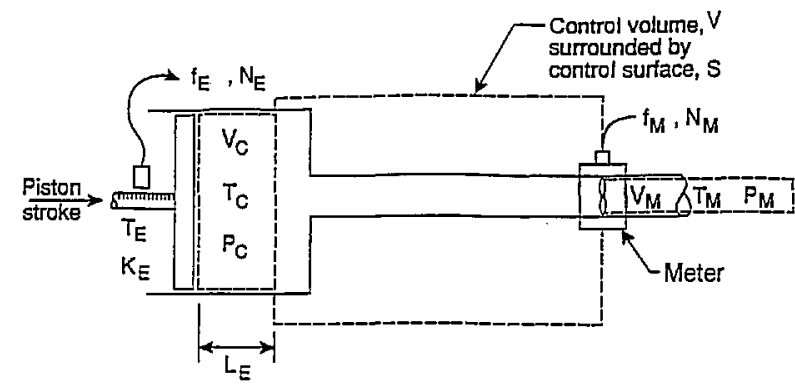

Fig. 8. Arrangement for using characterized calibrator to calibrate a turbine-type flowmeter at non-reference conditions. 
As stated above after Eq. (41), the pulse totals from the meter and the encoder have to correspond to the same displaced volume or time interval. If compensations are needed to achieve this correspondence, these should be done and results used in Eq. (53).

By normalizing this meter factor, $K_{\mathrm{M}}$ and the fluid flowrate using the non-reference meter diameter, $D_{\mathrm{M}}$, and fluid kinematic viscosity, $v$, we obtain Strouhal and Reynolds or Roshko numbers

$$
S t=f_{\mathrm{M}} D_{\mathrm{M}} / U_{\mathrm{M}}=C_{1} K_{\mathrm{M}} D_{\mathrm{M}}^{3},
$$

where $C_{1}=\pi / 4$, and

$$
R e=D_{M} U_{M} / v
$$

or

$$
R o=\frac{f_{\mathrm{M}} D_{\mathrm{M}}^{2}}{v} .
$$

Using these dimensionless parameters, the performance for the meter can be plotted; results should be as shown in Fig. 7. As noted above in Eqs. (43)-(45), the characteristics of meter factor and diameter at reference and non-reference conditions are interrelated and the dependence of the fluid's kinematic viscosity can be written functionally as

$$
v=\nu_{0}\left[T, T_{0}, P, P_{0}\right]
$$

With the performance curve given in Fig. 7 and the relationships given in Eqs. (43)-(45), or (54)(57), one is now ready to use the flowmeter to make a flowrate measurement.

\section{Using a Turbine-Type Flowmeter To Make a Measurement \\ 4.1 Reference Conditions}

Given that the meter performance characteristics are as shown in Fig. 7, or less preferably but more conventionally as in Fig. 9, one can quantify the meter linearity over a specified flowrate range. The meter linearity is conventionally the average of the maximum and minimum values of the meter factor (Strouhal number) over this range; normalized by the average meter factor, see [ 3 and 10]. For the meter performance shown in Fig. 7, the mean value of the Strouhal Number, $\overline{S t}$ gives the mean meter factor, via

$$
\bar{K}_{\mathrm{M} 0}=\frac{\overline{S t}}{C_{1} D_{\mathrm{M} 0}^{3}},
$$

where $C_{1}=\pi / 4$. The flowrate is determined via

$$
\dot{V}_{\mathrm{M} 0}=\frac{f_{\mathrm{M} 0}}{\bar{K}_{\mathrm{M} 0}}=\frac{C_{1} D_{\mathrm{M} 0}^{3} f_{\mathrm{M} 0}}{\overline{S t}} .
$$

This result would pertain to any flowrate over the range specified for the meter's linearity.

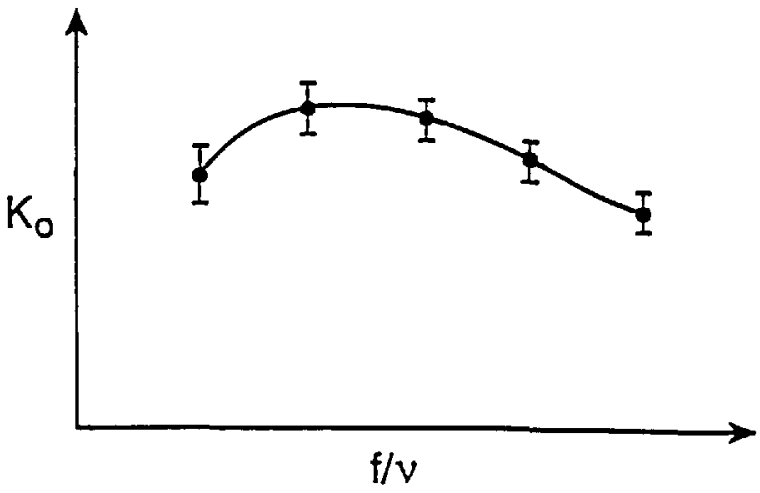

Fig. 9. Conventional performance plot for a turbine-type flowmeter.

If it is desired to improve the accuracy of this flowrate determination, this could be done by using, for example, the curve shown in Fig. 7 or close approximations to it. With advances in today's computer technology, this type of process can be readily installed in the secondary devices used with flowmeters. For the specific frequency from the meter, the Roshko number can be calculated directly and then used to determine the corresponding Strouhal number. For the case where the meter is characterized using Strouhal and Reynolds parameters, the process to determine an accurate flowrate should be iterative. This iteration process should begin using a mean value of meter factor, such as given in Eq. (58), this value of meter factor enables a computation of the flowrate via Eq. (59). Using this flowrate, the Reynolds number can be computed and then used to get the corresponding Strouhal number from the calibration curve and a refined value of flowrate. This process should be repeated until satisfactorily small changes are found in successive results. In this way, the accuracy level for the flowrate determination can be increased over the level associated with the meter's linearity. This can be done to the precision level associated with a specific flowrate as 
quantified in the calibration process. The resulting enhanced meter performance could amount to significant improvements in measurement accuracy. In the following, a Strouhal-Reynolds characterization of meter performance will be used since it is more conventional in fluid mechanics and since it may require the iteration procedure, described above, to be used.

\subsection{Non-Reference Conditions}

To describe meter performance in non-reference conditions, the meter characteristics shown in Fig. 7 will be used. The reason for this is that the complete, non-dimensional assessment of meter frequency effects and fluid inertial and viscous effects are not complete in Fig. 9. For this reason, the non-reference meter diameter, $D_{\mathrm{M}}$, and frequency, $f_{M}$, and the fluid's kinematic viscosity, $v$, should be used, in compatible units, to produce the Reynolds number for the non-reference conditions. This Reynolds number produces, using Fig. 7, the corresponding Strouhal number which with the meter diameter, $D_{\mathrm{M}}$, gives the meter factor, $K_{\mathrm{M}}$. The flowrate measurement is then obtained using

$$
\dot{V}_{\mathrm{M}}=\frac{f_{\mathrm{M}}}{\bar{K}_{\mathrm{M}}}=\frac{C_{1} f_{\mathrm{M}} D_{\mathrm{M}}^{3}}{\overline{S t}}
$$

This flowrate is correctly converted to reference conditions by specifying that the Strouhal number is the same for the non-reference and reference conditions, specified by this Reynolds number, i.e.,

$$
S t=C_{1} \frac{f_{\mathrm{M}} D_{\mathrm{M}}^{3}}{\dot{V}_{\mathrm{M}}}=C_{1} \frac{f_{\mathrm{M} 0} D_{\mathrm{M} 0}^{3}}{\dot{V}_{\mathrm{M} 0}} .
$$

Therefore

$$
\dot{V}_{\mathrm{M} 0}=\dot{V}_{\mathrm{M}} \frac{f_{\mathrm{M} 0}}{f_{\mathrm{M}}}\left(\frac{D_{\mathrm{M} 0}}{D_{\mathrm{M}}}\right)^{3} .
$$

The reference to non-reference frequency ratio is obtained by specifying that Reynolds number similarity exists for these two conditions, i.e.,

$$
R e=\frac{f_{\mathrm{M}} D_{\mathrm{M}}^{2}}{(S t) v_{\mathrm{M}}}=\frac{f_{\mathrm{M} 0} D_{\mathrm{M} 0}^{2}}{(S t) v_{\mathrm{M} 0}} .
$$

It is noted that this is equivalent to stipulating that Roshko number similarity exists for these two conditions. From Eq. (63)

$$
\frac{f_{\mathrm{M} 0}}{f_{\mathrm{M}}}=\frac{v_{\mathrm{M} 0}}{v_{\mathrm{M}}}\left(\frac{D_{\mathrm{M}}}{D_{\mathrm{M} 0}}\right)^{2}
$$

and

$$
\dot{V}_{M 0}=\frac{C_{f_{\mathrm{M}} D_{\mathrm{M} 0}^{3}}^{3}}{S t}\left(\frac{\mu_{\mathrm{M} 0}}{\mu_{\mathrm{M}}}\right) \frac{\left[1+2 \alpha_{\mathrm{M}}\left(T_{\mathrm{M}}-T_{\mathrm{M} 0}\right)\right]\left[1+\frac{\left(P_{\mathrm{M}}-P_{\mathrm{M} 0}\right) D_{\mathrm{M} 0}}{t_{\mathrm{M} 0} E_{\mathrm{M}}}\right]}{\left[1+3 \alpha_{\mathrm{F}}\left(T_{\mathrm{M}}-T_{\mathrm{M} 0}\right)\right]\left[1-\frac{\left(P_{\mathrm{M}}-P_{\mathrm{M} 0}\right)}{E_{\mathrm{F}}}\right]} .
$$

It is apparent that, to obtain high accuracy flowrate measurements using the procedures described above, appropriately high accuracy measurements are required for the component measurement systems and for the pertinent material properties as shown in Eq. (65). In turn, it appears feasible that once systematic uncertainties are satisfactorily removed from calibration facilities, the measurement processes in calibration laboratories, and the measurement systems making on-line measurements will be commensurately improved and the uncertainty levels for these measurements can be predicted using such Eqs. as (2), (10), (25), and (65).

\section{Discussion}

The above-derived results can, for the sake of brevity, be assessed by considering the effects of temperature and pressure on the respective factors - the calibrator and flowmeter constants and the flowrate measurement at reference conditions. To do this Table 1 shows, for specific material conditions and geometrical sizes, the variations associated with temperature and pressure effects separately and then summed together.

The results shown in the first row of Table 1 present the variations in calibrator constant $K_{\mathrm{co}}$ determined using geometrical measurement methods for variations of $\pm 1{ }^{\circ} \mathrm{C}$ in temperature and $\pm 1 \times 10^{5} \mathrm{~Pa}(1 \mathrm{~atm})$ in pressure. The material properties and geometrical assumptions are given under the headings of the respective columns. The worst-case combination of temperature and pressure variations taken separately are given in columns 7 and 12, respectively. These results are obtained by adding the absolute values of the component contributions. The total worst-case combination for temperature and pressure variations taken together is given in the column at the right side of the table. Accordingly, the total temperature effect on $K_{\mathrm{Co}}$ in the measurement method is five times larger than the pressure effect and the total of these gives an imprecision of $\pm 0.006 \%$. 
Table 1. Temperature and pressure effects

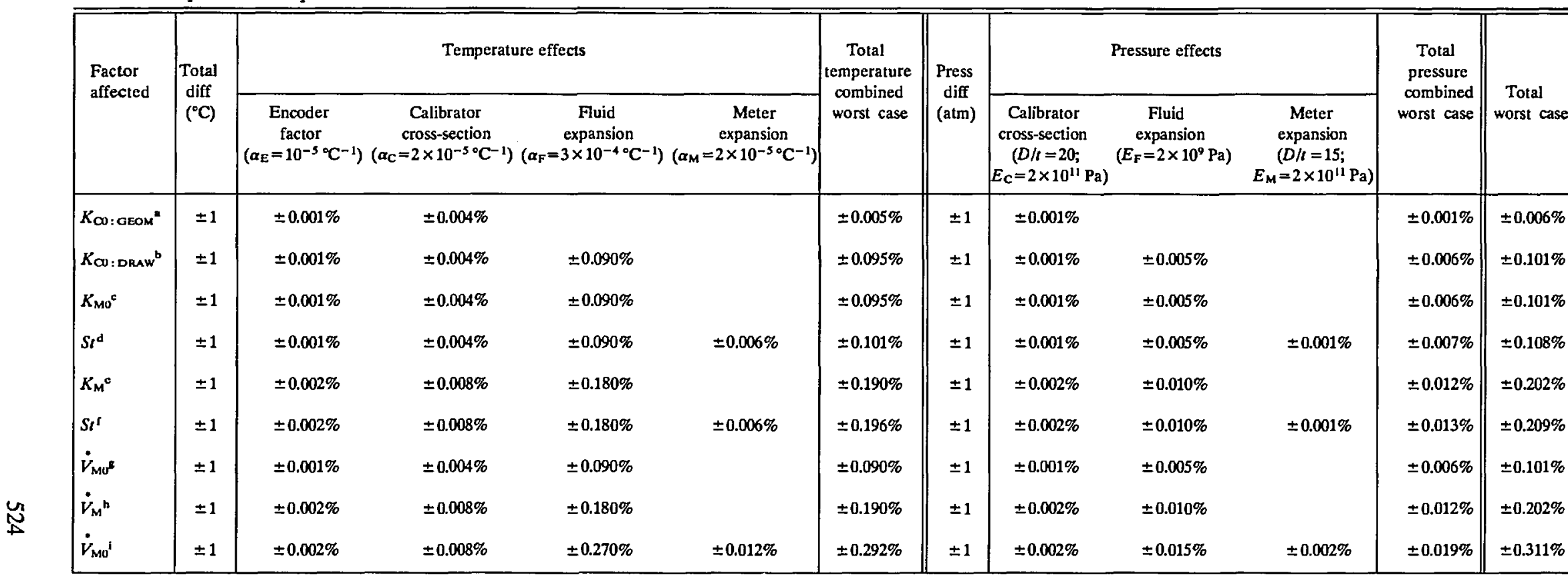

a Determined via Eq. (10) at non-reference conditions.

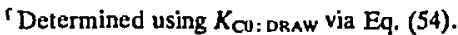

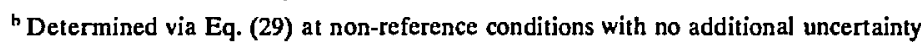
for the encoder or the collection volume.

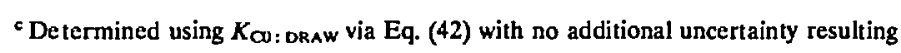

from encoder or meter outputs.

'Determined using $K_{\mathrm{CU} \text { : DRAw }}$ via Eq. (43) in reference conditions.

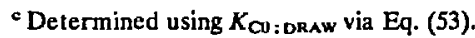

getermined using $K_{\text {Mo }}$ via Eq. (59) with no additional uncertainty resulting from the meter output.

" Determined using $K_{M}$ via Eq. (60) with no additional uncertainty resulting from meter output.

i Determined using Eq. (65) with not additional uncertainty for meter output, reference meter dimension, and absolute viscosity. 
The results for $K_{\mathrm{c} 0}$ determined using the draw technique are shown in the second row. These give a total temperature variation of $\pm 0.095 \%$ owing mainly to fluid expansion effects. The pressure variation is noted to be a factor of about 16 less than this level and the total imprecision totals $\pm 0.101 \%$ which is about a factor of 20 larger than the level achieved using the geometrical measurement technique.

The results for the meter factor, $K_{\mathrm{M} 0}$, are given in the third row of the table. Here, at reference conditions, no additional uncertainties are shown over those for $K_{\mathrm{co}}$ in accord with Eq. (42).

The fourth row indicates that the total temperature variation for $S t$ is increased over that for $K_{\mathrm{Mo}}$ by the amount allocated for meter expansion. This produces the $\pm 0.101 \%$ uncertainty total for temperature which when added to the increased pressure total gives $\pm 0.108 \%$. This shows that while the Strouhal number is the preferred nondimensional parameter to characterize the frequency effects of a meter, it has more factors than the conventional meter factor, $K_{\mathrm{M} 0}$ and, therefore, it can have increased uncertainty. However, because the Strouhal number is a dimensionless ratio of frequency to inertial effects in the meter it should be successful in producing more satisfactory metering results for widely ranging conditions than can be done using a dimensional quantity such as $K_{\text {MO. }}$

The fifth and sixth rows express the uncertainties for $K_{\mathrm{M}}$ and the corresponding Strouhal number in a manner analogous to that used to obtain values in rows three and four. However, as shown in Eq. (53) the uncertainties attributed to $K_{\mathrm{CO}}$ are increased appropriately due to encoder, calibrator, and fluid effects; and, in the case for $S t$, meter effects. It is noted that the totaled uncertainties have essentially doubled in comparison with those for $K_{\mathrm{MO}}$.

While it is recognized that the conditions of $\pm 1^{\circ} \mathrm{C}$ and $\pm 1 \times 10^{5} \mathrm{~Pa}(1 \mathrm{~atm})$ pressure variation can be termed large, it should be recognized that no uncertainty has been allocated in Table 1 for the uncertainty with which the material properties and geometrical dimensions are known or have been determined. As well, it should be recognized that these assumed conditions of $\pm 1{ }^{\circ} \mathrm{C}$ and $\pm 1 \times 10^{5}$ $\mathrm{Pa}(1 \mathrm{~atm}) \mathrm{can}$ in reality understate the actual variations that may exist in real situations where flowrate measurements can be attempted in harsh, hostile environments.
It should be emphasized that the above discussion deals only with the uncertainties associated with temperature and pressure imprecision and does not take into account contributions from flowmeter imprecision such as the variability of detecting meter pulses. Additionally, systematic errors which can greatly exceed the levels of imprecision are not included in any of the above.

- A summary of the equations derived for characterizing piston-type, encoded-stroke calibrators, their calibration procedures, and the subsequent use of calibrated turbine meters is given in Appendix C. These equations are found to be quite simple when reference conditions prevail. However, reference conditions are practically fictitious and therefore the performance of all of these devices should be considered as occurring in nonreference conditions. Given the capabilities available in today's computers, it is felt that the complete equations for these types of devices should be installed in the controlling and processing software so that when temperature and or pressure conditions become significant in these processes the results are accurate. Using these equations when temperature and or pressure effects are not significant produces negligible differences from the results at reference conditions.

\section{Conclusions}

High accuracy fluid measurements can be attained when the important factors affecting the performances of both flowmeter calibrators and fluid meters are properly taken into account in the measurement processes of these devices. To do this - to first order temperature and pressure effects on both the calibrator and the meter as well as on the fluid-the equations derived above should be used as the basic system models for calibrator and meter. Specific features of calibrators need to be analyzed and, where pertinent, appropriate modifications to the above-derived equations should be made. Calibrators and metering units need to be properly instrumented and operated according to the required assumptions and techniques for handling the data. Where further increases in flow measurement accuracy are needed, either more accurate descriptions of currently considered factors should be made or additional factors not currently considered should be assessed and included as pertinent, or both. 


\section{Appendix A. Cross-Sectional Area Changes in the Cylinder of the Calibrator}

The fluid pressure and temperature inside the cylinder of the calibrator can enlarge or reduce the cross-sectional areas of this cylinder, see Fig. 1. As well, geometrical changes of the rod or tube connected to the piston can also contribute to changes in this cross-sectional area. Of course, knowledge of specific geometries and material properties are crucial to characterizing these changes. In the following it is assumed that a generic cylinder and rod geometry exist as sketched in Fig. 1.

First, thermal expansion will increase the diameters of the cylinder and the connecting tube or rod via the first order approximations

$$
D=D_{0}\left[1+\alpha_{\mathrm{C}}\left(T_{\mathrm{C}}-T_{0}\right]\right.
$$

and

$$
d=d_{0}\left[1+\alpha_{\mathrm{r}}\left(T_{\mathrm{s}}-T_{0}\right],\right.
$$

where, in compatible units, $D$ and $d$ and $D_{0}$ and $d_{0}$ are the cylinder and tube diameters at nonreference and reference conditions, respectively. The linear expansion coefficients for cylinder and tube or rod are $\alpha_{\mathrm{C}}$ and $\alpha_{\mathrm{r}}$, respectively, and $T_{\mathrm{C}}$ and $T_{\mathrm{r}}$ are the corresponding temperatures. These diametral enlargements will produce an increased cross-sectional area via the first order approximation

$$
\bar{A}_{\mathrm{C}}=\bar{A}_{\mathrm{Co}}\left[1+2 \alpha_{\mathrm{C}}\left(T_{\mathrm{C}}-T_{0}\right],\right.
$$

where $\bar{A}_{\mathrm{C}}$ and $\bar{A}_{\mathrm{co}}$ are, respectively, the annular areas between cylinder and rod as averaged over the appropriate piston displacement. The linear expansion coefficient of the rod or tube is assumed to be the same as that for the cylinder.

Second, pressure effects can change the crosssectional area through the enlargement of the calibrator cylinder and the contraction of the rod or tube connected to the piston. The azimuthal or "hoop" stress, $\sigma_{\theta}$, produced in the calibrator cylinder can be shown to be

$$
\sigma_{\theta}=\left(P_{\mathrm{C}}-P_{0}\right) D_{\mathrm{c}} / 2 t_{\mathrm{C}},
$$

where $P_{C}-P_{0}$ is the pressure difference between the pressure in the cylinder and the reference pressure outside the cylinder. The quantities $D_{\mathrm{C}}$ and $t_{\mathrm{C}}$ are, respectively, the inside diameter and the thickness of the cylinder. The azimuthal strain produced by this stress is assumed to be

$$
\epsilon_{\theta}=\sigma_{\theta} / E_{\mathrm{C}},
$$

where transverse effects are neglected and where $E_{\mathrm{c}}$ is the modulus of elasticity of the material of the calibrator. This azimuthal strain increases the circumference of the calibrator cylinder via

$$
C=C_{0}\left(1+\epsilon_{\theta}\right),
$$

where $C$ and $C_{0}$ are, respectively, the inside circumferences of the cylinder in stressed and unstressed conditions. This produces an increase, to first order, in the cylinder's averaged crosssectional area of

$$
\bar{A}_{\mathrm{C}}=\frac{\bar{C}^{2}}{4 \pi}=\frac{\bar{C}_{0}^{2}}{4 \pi}\left[1+\frac{\left(P_{\mathrm{C}}-P_{0}\right) D_{\mathrm{C} 0}}{t_{\mathrm{co}} E_{\mathrm{C}}}\right]
$$

or since $\bar{A}_{\mathrm{CO}}=\bar{C}_{0}{ }^{2} / 4 \pi$,

$$
\bar{A}_{\mathrm{C}}=\bar{A}_{\mathrm{CO}}\left[1+\frac{\left(P_{\mathrm{c}}-P_{0}\right) D_{\mathrm{co}}}{t_{\mathrm{c} 0} E_{\mathrm{c}}}\right]
$$

where $D_{\mathrm{Co}}$ and $t_{\mathrm{co}}$ are the diameter and thickness, respectively, of the calibrator cylinder at reference conditions. Typical values for the ratio $D_{\mathrm{co}} / t_{\mathrm{co}}$ could be 10 to 20 .

In similar fashion, the cylinder pressure in excess of the reference pressure, $P_{0}$ at which condition the reference dimensions are determined can reduce the outside diameter of the tube connected to the piston. Since the deformation of a tube should, for the same material and diameter, exceed that for a solid rod, it shall be considered here. Therefore, the cross-sectional area of the tube connected to the piston would be

$$
\bar{A}_{\mathrm{t}}=\bar{A}_{\mathrm{t} 0}\left[1-\frac{\left(P_{\mathrm{c}}-P_{0}\right) D_{\mathrm{t} 0}}{t_{\mathrm{t} 0} E_{\mathrm{t}}}\right],
$$

where $D_{\mathrm{t} 0}$ and $t_{\mathrm{t} 0}$ are, respectively, the outside diameter and the thickness of the wall of the tube connected to the piston at reference conditions. The quantity $E_{\mathrm{T}}$ is the modulus of elasticity of the tube material, at reference conditions.

It is generally and safely assumed that the tube contraction effect expressed in Eq. (A.1.9) is negligible in comparison to the effects of temperature on the inner diameter of the calibrator. Therefore, it is assumed that the annular cross-sectional area between cylinder and tube is that expressed in Eq. (A.1.3) and the effect of pressure on this annular area is expressed in Eq. (A.1.8). However, where 
specifics indicate that other compensations need to be made, other approximations can and should be done. The combined effect of pressure and temperature on the averaged cross-sectional area of the cylinder of the calibrator is,

$$
\bar{A}_{\mathrm{C}}=\bar{A}_{\mathrm{Co}}\left[1+2 \alpha_{\mathrm{c}}\left(T_{\mathrm{C}}-T_{\mathrm{CO}}\right]\left[1+\frac{\left(P_{\mathrm{c}}-P_{0}\right) D_{\mathrm{c} 0}}{E_{\mathrm{c} t} t_{\mathrm{co}}}\right]\right. \text {. }
$$

\section{Appendix B. Turbine Meter Data Processing}

Conventional practice in processing and using turbine-type flowmeter data began with plotting the meter $K$ factor in pulses per volume units as a function of meter frequency, $f$; see Fig. A.2.1 and [5-8]. In this figure, the bracketed dots are intended to represent the mean values and the scatter obtained for the $K$ factors at respective frequencies. For fluid and flow conditions which precisely duplicate those for which the meter calibration was performed, this practice produced acceptable results. However, when fluid or flow conditions deviated from those of the calibration, it was found that results could be unacceptable. An example is indicated in Fig. A.2.1. The lines for which the liquid viscosities are $\mu_{1}$ and $\mu_{2}$, respectively, indicate that different meter performance occurs at low flowrates when the fluid dynamic viscosity, $\mu_{2}$ is greater than the value $\mu_{1}$ used for the calibration.

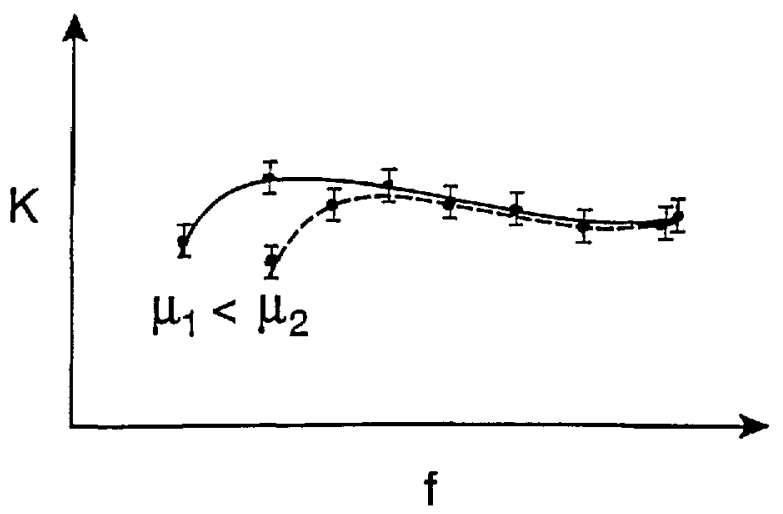

Fig. A.2.1 Conventional format for processing turbine-type flowmeter data.

Flowmeter performance which deviates from that of the calibration conditions at low flowrates is explained by citing the deviant phenomena which have, because of the different fluid or flow conditions, become significant in comparison to the phenomena which prevailed during calibration. Shafer and Lee have resolved several situations involving viscous effects in specific flowmeter geometries [6,8]. From such efforts have come Universal Viscosity Curves (UVC) i.e., plots of meter factor versus the ratio of meter frequency to fluid kinematic viscosity. A typical UVC is shown in Fig. A.2.2. The ordinate, $K_{0}$, is the meter factor referenced to a selected reference temperature via, see [10],

$$
K_{0}=K\left[1+3 \alpha_{M}\left(T-T_{0}\right] .\right.
$$

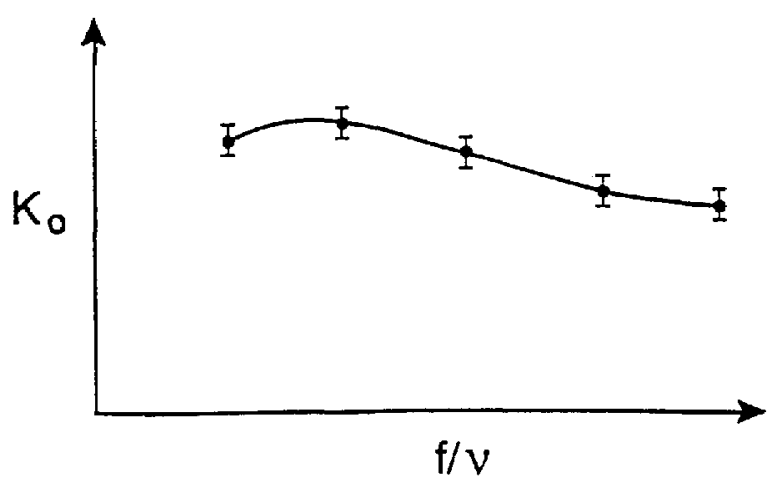

Fig. A.2.2 Universal Viscosity Curve (UVC) for processing turbine-type flowmeter data.

Deviations of flowmeter performance characteristics from UVC's can be explained by citing further deviants, such as lubricity, cavitation, extreme temperature or pressure effects on fluid properties, etc., see [5-8].

When the turbine meter is to be used in temperature conditions different from those of the reference or calibration conditions, temperature effects may be compensated for by producing corrections for the meter factor $K$, as found in some standards, see [10]. This ISA standard produces an underived correction that is based upon the thermal expansion for the material of the meter body. This correction is effective in predicting trends for the case where the meter body and the turbine wheel material are the same. Where these materials are different, this correction can give erroneous results, for example, in the extreme situation where the turbine wheel has expanded to touch the inner wall of the meter body, thus stopping the wheel's rotation. In such a situation the meter factor should be zero yet the ISA correction would not 
give this result. Therefore, further evolution is needed for conventional turbine-type flowmeter practice-beyond the UVC methods.

Turbine meter performance is most properly characterized by specifying and quantifying, over the pertinent ranges of fluid and flow conditions, the significant dimensionless parameters which influence meter performance. To do this, the dimensional quantities that are involved in turbinetype flowmetering are cited as shown in Fig. A.2.3. These five dimensional quantities - fluid density $\rho$, and viscosity $\mu$, the flow velocity $U$, the meter frequency $f$, and the meter diameter, $D$ are described in terms of three independent unitslength, time, and mass or force. Consequently, there are two dimensionless parameters to characterize the performance of this meter. These dimensionless parameters can take many forms. Conventional fluid mechanical practice would produce parameters expressing ratios of meter frequency effects to fluid inertial effects, i.e., the Strouhal number and the fluid inertial to viscous effects, i.e., the Reynolds number. These are written

$$
S t=f D / U
$$

and

$$
R e=\frac{D U \rho}{\mu}=\frac{D U}{v} .
$$

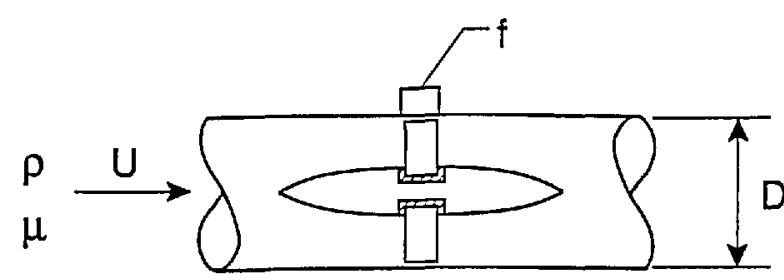

Fig. A.2.3 Turbine meter configuration.

However, turbine meters are designed to have frequencies proportional to volumetric flowrates. The constant of proportionality is the reciprocal of the meter factor. Since the constancy of this meter factor, i.e., the linearity of the meter over the flowrate (frequency) range is generally taken to be a measure of the quality of the meter, it has become conventional turbine meter practice to characterize meters via their $K$ factor versus frequency dependence. In non-dimensional format, this can be done by specifying meter performance using a Strouhal number that is dependent upon the product of the Strouhal and Reynolds numbers, i.e., $f D^{2} / v$. This parameterization is essentially that known as the
UVC except for the factors involving the meter diameter, $D$, raised to an exponent. This product has been referred to as the Roshko number, $R o$,

$$
R o=\frac{f D^{2}}{v}
$$

see [9]. Alternatively, the pair of parameters, $S t$ and $R e$ could also be used to characterize the meter's performance. In either case, only two parameters are needed to characterize the system sketched in Fig. A.2.3.

In all of the above, the effect of different meter geometries or a different turbine wheel is not considered. This is proper where the meter geometry is not changed and where the same turbine wheel and bearings, etc. are used and where the turbine wheel and the meter body are made of the same material. Under these circumstances, the above parameterization of the five dimensional quantities $\rho, \mu, U, D$, and $f$ is completed with the formulation of the Strouhal and Reynolds or Roshko numbers. Using this formulation the performance of the calibrated meter should enable the meter to be satisfactorily used over a range of conditions similar to those encountered in the calibration.

If the situation is changed as shown in Fig. A.2.4 so that the turbine wheel diameter, $d$, is included to produce six dimensional quantities, then three dimensionless parameters should be formed. The turbine wheels that are considered here are geometrically scaled versions of each other, i.e., they have the same number of blades, the same blade shape and only differ in the diameter, $d$. The nondimensionalization can be achieved by choosing the third dimensionless parameter to be $\beta=d / D$, the ratio of turbine wheel to inside pipe diameter. The three parameter performance is sketched in Fig. A.2.5. It is noted that when the turbine wheel and meter body are the same material and when only thermal expansion effects are considered, $\beta$ remains constant with changes in temperature, i.e.,

$$
\beta=\frac{d}{D}=\frac{d_{0}\left[1+\alpha_{\mathrm{r}}\left(T_{\mathrm{r}}-T_{0}\right]\right.}{D_{0}\left[1+\alpha_{\mathrm{M}}\left(T_{\mathrm{M}}-T_{0}\right]\right.},
$$

when $T_{\mathrm{r}}=T_{\mathrm{M}}$ and $\alpha_{\mathrm{r}}=\alpha_{\mathrm{M}}$ this diameter ratio is $d_{0} / D_{0}$.

When turbine wheel and meter body are different materials and when $\alpha_{\mathrm{r}}>\alpha_{\mathrm{M}}$, the beta ratio is not constant and a condition for the linear expansion coefficients and the fluid flowrate can be derived for which $T_{M}=T_{s}$ and $\beta=1$. This would 
indicate that the turbine blade tips touch the inside of the meter body thus stopping the wheel. This condition is, of course, contrived in order to illustrate the point that $\beta$ variation can produce meter performance variation and in extreme limits can radically alter the graphs of meter performance.

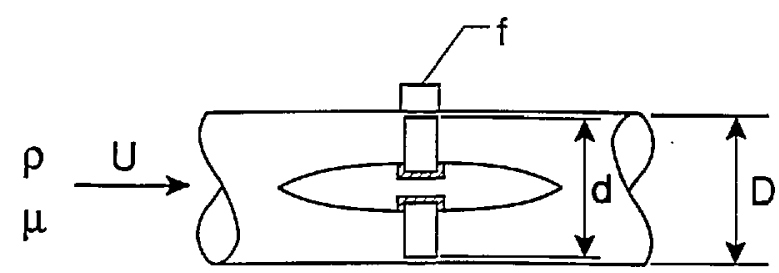

Flg. A.2.4 Turbine meter configuration with the turbine wheel diameter, $d$, considered as a parameter.

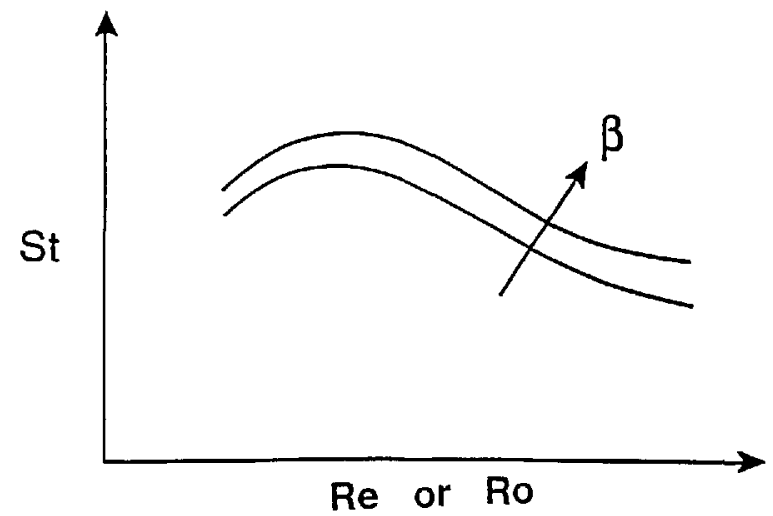

Fig. A.2.5 Non-dimensional turbine meter performance.

If pressure effects are not negligible in altering the diameter of the meter body but are negligible in affecting the diameter of the turbine wheel, $\beta$ is altered, to first order in temperature and pressure, separately, via

$$
\beta=\frac{d_{0}\left[1+\alpha_{\mathrm{r}}\left(T_{\mathrm{r}}-T_{0}\right)\right]}{D_{0}\left[1+\alpha_{\mathrm{M}}\left(T_{\mathrm{M}}-T_{0}\right]\left[1+\frac{\left(P_{\mathrm{M}}-P_{0}\right) D_{\mathrm{M} 0}}{2 t_{\mathrm{M} 0} E_{\mathrm{M}}}\right]\right.}
$$

By so incorporating thermal and pressure effects using $S t, R e$ or $R o$, and $\beta$ parameters into performance curves as sketched in Fig. A.2.6, widely varying metering conditions should be successfully handled.

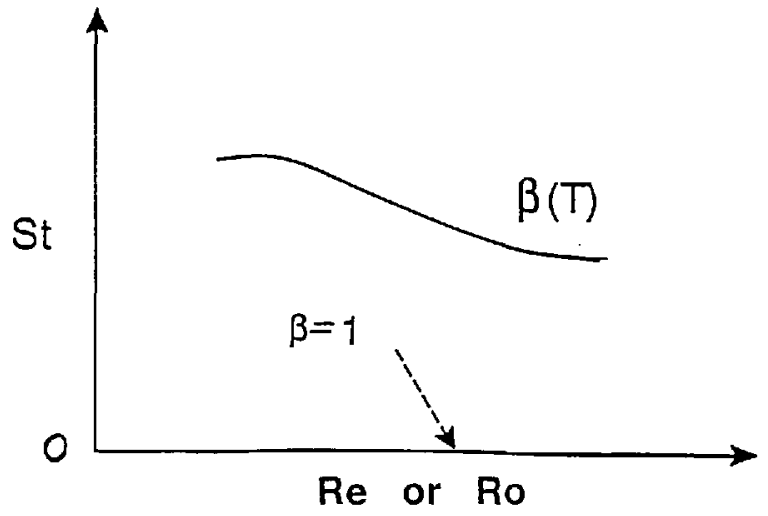

Fig. A.2.6 Sketch of expected turbine meter performance where $\beta \rightarrow 1$.

It is concluded that turbine-type flowmeter performance should be handled non-dimensionally. Pertinent corrections are then most clearly seen and most easily performed using the appropriate, first-order, relationships for the thermal and pressure effects. In this way high levels of flowmeter performance can be expected and achieved.

\section{Appendix C. Equations Summary}

The equations in Appendix $\mathrm{C}$ are numbered as in the main text.

\section{Calibrator Characterization:}

a. Geometrical Measurement Method-Reference Conditions (see p. 513)

$$
K_{\mathrm{C} 0}=\frac{N_{\mathrm{E} 0}}{V_{\mathrm{C} 0}}=\frac{L_{\mathrm{E} 0} K_{\mathrm{E} 0}}{\bar{A}_{\mathrm{C} 0} L_{\mathrm{E} 0}}=\frac{K_{\mathrm{E} 0}}{\bar{A}_{\mathrm{C} 0}}
$$

b. Geometrical Measurement Method-NonReference Conditions (see p. 515)

$$
K_{\mathrm{CO}}=K_{\mathrm{C}} \frac{\left[1+\alpha_{\mathrm{E}}\left(T_{\mathrm{E}}-T_{0}\right)\right]}{\left[1-2 \alpha_{\mathrm{C}}\left(T_{\mathrm{C}}-T_{0}\right]\left[1-\frac{\left(P_{\mathrm{C}}-P_{0}\right) D_{\mathrm{C} 0}}{t_{\mathrm{C} 0} E_{\mathrm{C}}}\right]\right.}
$$

where

$$
K_{\mathrm{C}}=\frac{N_{\mathrm{E}}}{V_{\mathrm{C}}}
$$

c. Draw Technique-Reference Conditions (see p. 516)

$$
K_{\mathrm{CO}}=N_{\mathrm{E} 0} / V_{\text {COLL'To }} \text {. }
$$


d. Draw Technique-Non-Reference Conditions (see p. 517)

$$
\frac{K_{\mathrm{CO}}=K_{\mathrm{C}}^{\prime}}{\left[1+2 \alpha_{\mathrm{C}}\left(T_{\mathrm{C}}-T_{0}\right)\right]\left[1+\frac{\left(P_{\mathrm{C}}-P_{0}\right) D_{\mathrm{CO}}}{t_{\mathrm{CO}} E_{\mathrm{C}}}\right]}
$$

where

$$
K_{\mathrm{C}}^{\prime}=N_{\mathrm{E}} / V_{\text {COLL'T }}^{\prime} .
$$

\section{Meter Calibration:}

a. Reference Conditions: (see p. 519)

$K_{\mathrm{M} 0}=\frac{f_{\mathrm{M} 0}}{f_{\mathrm{E} 0}} \frac{K_{\mathrm{E} 0}}{\bar{A}_{\mathrm{C} 0}}=\frac{N_{\mathrm{M} 0}}{N_{\mathrm{E} 0}} \frac{K_{\mathrm{E} 0}}{\bar{A}_{\mathrm{C} 0}}=\frac{N_{\mathrm{M} 0}}{N_{\mathrm{E} 0}} \cdot K_{\mathrm{C} 0}=\frac{f_{\mathrm{M} 0}}{f_{\mathrm{E} 0}} \cdot K_{\mathrm{C} 0}$.

Data Processing: (see p. 519)

$$
\begin{gathered}
S t=\frac{f_{\mathrm{M} 0} D_{\mathrm{M} 0}}{U_{\mathrm{M} 0}}=C_{1} K_{\mathrm{M} 0} D_{\mathrm{M} 0}^{3} \propto K_{\mathrm{M} 0} D_{\mathrm{M} 0}^{3}, \\
R e=\frac{D_{\mathrm{M} 0} U_{\mathrm{M} 0}}{v_{0}}, \\
R_{0}=\frac{f_{\mathrm{M} 0} D_{\mathrm{M} 0}^{2}}{w_{0}} .
\end{gathered}
$$

b. Non-Reference Conditions: (see p. 521)

$$
\begin{aligned}
& K_{M}=\frac{f_{M}}{f_{\mathrm{E}}} K_{\mathrm{C}} \frac{\rho_{M}}{\rho_{\mathrm{C}}}=\frac{N_{M}}{N_{\mathrm{E}}} K_{\mathrm{CO}} \\
& \times \frac{\left[1-\alpha_{\mathrm{E}}\left(T_{\mathrm{E}}-T_{0}\right)\right]\left[1+3 \alpha_{\mathrm{E}}\left(T_{\mathrm{C}}-T_{\mathrm{M}}\right)\right]}{\left[1+2 \alpha_{\mathrm{C}}\left(T_{\mathrm{C}}-T_{0}\right)\right]\left[1+\frac{\left(P_{\mathrm{C}}-P_{0}\right) D_{\mathrm{CO}}}{t_{\mathrm{CO}} E_{\mathrm{C}}}\right]\left[1+\frac{\left(P_{\mathrm{C}}-P_{\mathrm{M}}\right)}{E_{\mathrm{F}}}\right]} .
\end{aligned}
$$

Data Processing: (see p. 522)

$$
\begin{gathered}
S t=f_{\mathrm{M}} D_{\mathrm{M}} / U_{\mathrm{M}}=C_{1} K_{\mathrm{M}} D_{\mathrm{M}}^{3}, \\
R e=D_{\mathrm{M}} U_{\mathrm{M}} / v, \\
R o=\frac{f_{\mathrm{M}} D_{\mathrm{M}}^{2}}{v} .
\end{gathered}
$$

\section{Flow Measurement:}

a. Reference Conditions: (see p. 522)

$$
\dot{V}_{\mathrm{M} 0}=\frac{f_{\mathrm{M} 0}}{\bar{K}_{\mathrm{M} 0}}=\frac{C_{1} D_{\mathrm{M} 0}^{3} f_{\mathrm{M} 0}}{\overline{S t}} .
$$

b. Non-Reference Conditions: (see p. 523)

$$
\dot{V}_{\mathrm{M}}=\frac{f_{\mathrm{M}}}{\bar{K}_{\mathrm{M}}}=\frac{C_{1} f_{\mathrm{M}} D_{\mathrm{M}}^{3}}{\overline{S t}},
$$

$$
\dot{V}_{\mathrm{M} 0}=\frac{C_{1} f_{\mathrm{M}} D_{\mathrm{M}}^{3}}{S t}\left(\frac{\mu_{\mathrm{M} 0}}{\mu_{\mathrm{M}}}\right) \frac{\left[1+2 \alpha_{\mathrm{M}}\left(T_{\mathrm{M}}-T_{\mathrm{M} 0}\right)\right]\left[1+\frac{\left(P_{\mathrm{M}}-P_{\mathrm{M} 0}\right) D_{\mathrm{M} 0}}{t_{\mathrm{M} 0} E_{\mathrm{M}}}\right]}{\left[1+3 \alpha_{\mathrm{F}}\left(T_{\mathrm{M}}-T_{\mathrm{M} 0}\right)\right]\left[1-\frac{\left(P_{\mathrm{M}}-P_{\mathrm{M} 0}\right)}{E_{\mathrm{F}}}\right]} .
$$

\section{Acknowledgment}

This manuscript has evolved and been assembled as the results of many contributions, direct and indirect, from many sources-NIST staff, DoD metrologists, industrial personnel, and the flow measurement staff members in several national laboratories in Canada, Italy, and the U.K. Special thanks are due to K.R. Benson, NIST, Gaithersburg, for his reactions and contributions all through this effort; ideas and suggestions have also been incorporated from NIST Fluid Flow Group staff members: W. G. Cleveland, D. E. Hess, and N. E. Mease. It is especially pertinent to acknowledge the significant inputs and contributions made to these tests and this paper by V. Grabe, P. Olivier, and D. Ruffner. The secretarial contributions made by Mrs. G. M. Kline, NIST Fluid Flow Group, toward the production of this document are most gratefully acknowledged. In the DoD areas, it is pertinent to cite, alphabetically: Air Force: W. Callis, K. Hartz, B. Keeley, and J. Sharp; Army: J. Miller and D. Sherk; Navy: R. Cheesman, M. Gee, B. McBurney, and D. Todd. 


\section{References}

[1] G. E. Mattingly, Calibration Techniques and Traceability, in Developments in Flow Measurement I, ed. R. W. W. Scott, Applied Science Publishers, New York and London (1982).

[2] G. E. Mattingly, Volume Flow Measurement, in Fluid Mechanics Measurements, Hemisphere Publishing Co., New York (1979).

[3] ASME/ANSI Standard: Glossary of Terms for Fluid Flowrate Measurement, MFC 1 M, 1991, ASME-New York.

[4] ASME/ANSI Standard: Measurement of Liquid Flow in Closed Conduits by Weighing Methods, MFC-9M, 1988, ASME-New York.

[5] R. A. Furness, Turbine Flowmeters, in Developments in Flow Measurement I, ed. R.W.W. Scott, Applied Science Publishers, New York and London (1982).

[6] M. R. Shafer, Performance Characteristics of Turbine Flowmeters, Trans. ASME, J. Basic Eng. 84, 1369-79 (1962).

[7] H. M. Hochreiter, Dimensionless Correlation of Coefficients of Turbine-Type Flowmeters, Trans. ASME 80, 1363-68 (1958).

[8] W. F. Z. Lee, and H. Karlby, A Study of the Viscosity Effect and Its Compensation on Turbine-Type Flowmeters, Trans. ASME, J. Basic Eng. 82, 717-28 (1960).

[9] S. Kohan, and W. H. Schwarz, Low Speed Calibration Formula for Vortex Shedding From Cylinders, Phys. Flds. 16 (9) 1528-9 (1973).

[10] ISA Recommended Practice Specification, Installation and Calibration of Turbine Flowmeters, ISA-RP 31.1, Instrument Society of America, Res. Tri. Pk. NC (1977).

\footnotetext{
About the author: Dr. George E. Mattingly is a mechanical engineer who leads the Fluid Flow Group in the Process Measurements, Division of the NIST Chemical Science and Technology Laboratory. The National Institute of Standards and Technology is an agency of the Technology Administration, U.S. Department of Commerce.
} 